Running head: Detecting others' trait levels

\title{
Judging personality from a brief sample of behavior: Detecting where others stand on trait continua
}

\author{
Wenjie $\mathrm{Wu}^{1}$, Elizabeth Sheppard ${ }^{2}$ and Peter Mitchell ${ }^{2}$ \\ ${ }^{1}$ School of Education, Lingnan Normal University, Zhanjiang, China \\ ${ }^{2}$ School of Psychology, University of Nottingham, UK
}

Word count: 11004 (excluding title page, abstract, references, figure captions, tables and figures)

Author note: Correspondence should be addressed to Wenjie Wu, School of Education, Lingnan Normal University, Cunjin Road No. 29, Chikan District, Zhanjiang 524048. Email: jie.w.wu@hotmail.com. Studies 1 and 2 were done at the University of Nottingham Malaysia campus for the first author's $\mathrm{PhD}$. The authors declare that there are no potential conflicts of interest with respect to the research, authorship, and publication of this article. 


\begin{abstract}
Trait inferences occur routinely and rapidly during social interaction, sometimes based on scant or fleeting information. In this research, participants (perceivers) made inferences of targets' big-five traits after briefly watching or listening to an unfamiliar target (a third party) performing various mundane activities (telling a scripted joke or answering questions about him/herself or reading aloud a paragraph of promotional material). Across three studies, when perceivers judged targets to be either low or high in one or more dimensions of the big-five traits they tended to be correct, but they did not tend to be correct when they judged targets as average. Such inferences seemed to vary in effectiveness across different trait dimensions and depending on whether the target's behavior was presented either in a video with audio, a silent video or just in an audio track - perceivers generally were less often correct when they judged targets as average in each of the big-five traits across various information channels (videos with audio, silent videos and audios). Study 3 replicated these findings in a different culture. We conclude with discussion of the scope and the adaptive value of this trait inferential ability.

Key Words: trait inferences, big-five traits, zero-acquaintance, thin slices of behavior
\end{abstract}




\section{Judging personality from a brief sample of behavior:}

\section{Detecting where others stand on trait continua}

Trait inferences occur routinely and rapidly during social interaction (Todorov \& Uleman, 2002, 2003, 2004; Uleman \& Saribay, 2012, for a review), sometimes based on scant or ephemeral information (Ambady, Bernieri, \& Richeson, 2000), such as a fleeting facial expression (Willis \& Todorov, 2006), a quick gait (Thoresen, Vuong, \& Atkinson, 2012), a voice offering a greeting (McAleer, Todorov, \& Belin, 2014) and a short get-acquainted conversation (Carney, Colvin, \& Hall, 2007). Being able to infer aspects of a person's character, or traits, is adaptive in that it influences the way we select, shape and maintain our social environments (Back \& Nestler, 2016), allowing us to decide who will be only nodding acquaintances and who may be enduring friends.

Research has already investigated whether or not various traits are perceptible (e.g., Albright, Kenny, \& Malloy, 1988; Back \& Nestler, 2016; Borkenau \& Liebler, 1992, 1993; Borkenau, Mauer, Riemann, Spinath, \& Angleitner, 2004; Carney et al., 2007; Funder, 2012; Funder, Kolar, \& Blackman, 1995; Kenny, Horner, Kashy, \& Chu, 1992; McLarney-Vesotski, Bernieri, \& Rempala, 2006; Thoresen, et al., 2012; Todorov, Pakrashi, \& Oosterhof, 2009), but the current research has a slightly different purpose. Past research usually tells us that people (henceforth 'perceivers') can systematically infer some aspects of personality traits; it does not tell us whether people's judgments differ at differing levels of a trait continuum. The aim, then, was to investigate perceivers' performance in detecting that another person (the target) is 
high, middle or low in each dimension of the big-five traits: Do people judge personality traits similarly at any point on the scale or do their judgments differ at different parts of the scale?

Using the zero-acquaintance procedure, where the perceiver is asked about a target's psychological traits neither with acquaintance nor prior knowledge (Norman \& Goldberg, 1966; Albright et al., 1988), a large number of studies have revealed above-chance levels of accuracy in judging some aspects of the big-five personality dimensions (Neuroticism (N), Extraversion (E), Openness to Experience (O), Agreeableness (A) and Conscientiousness (C)) in a wide variety of contexts (Back \& Nestler, 2016) ranging from physical appearance (Naumann, Vazire, Rentfrow, \& Gosling, 2009) to short samples of behavior (e.g., Borkenau et al., 2004; Carney et al., 2007; Thoresen, et al., 2012). After observing 'thin slices' of behavior (occupying less than five minutes, Ambady et al., 2000), sampled from mundane activities, such as reading aloud a standard text (Borkenau \& Liebler, 1992, 1993), performing an unstructured dyadic interaction (Carney et al., 2007), singing a song or doing a selfintroduction and so forth (Borkenau et al., 2004), perceivers can draw somewhat accurate inferences about $\mathrm{E}$ and $\mathrm{C}$ across different contexts but their performance in inferring the other three big-five dimensions seems to be inconsistent across different studies (e.g., Borkenau \& Liebler 1992; Borkenau et al., 2004; Carney et al., 2007; McLarney-Vesotski et al., 2006; Norman \& Goldberg, 1966; Wall, Taylor, Dixon, Conchie, \& Ellis, 2013; Watson, 1989). For instance, in the study by Borkenau et al (2004), after briefly observing the targets in trivial scenarios, perceivers could achieve 
significant agreement on the evaluation of $\mathrm{A}$, whereas in another study even in a carefully crafted trait-relevant situation, perceivers failed to make an accurate judgment of A (McLarney-Vesotski et al., 2006). Trait O is difficult to judge in some contexts (e.g., Borkenau \& Liebler, 1992; Wall et al., 2013) but can be judged consistently when targets performed a task of pantomime (Borkenau et al., 2004). Although trait $\mathrm{N}$ is low in visibility at zero acquaintance (Connelly \& Ones, 2010; Connolly, Kavanagh, \& Viswesvaran, 2007; Funder, 2012; Vazire, 2010), a recent study (Hirschüller, Egloff, Schmukle, Nestler, \& Back, 2015) suggested that strangers were sensitive to individual differences in $\mathrm{N}$ as long as targets were observed in socially stressful situations. All in all, the literature suggests that people can form somewhat accurate first impressions on the dimensions of $\mathrm{E}$ and $\mathrm{C}$ or other traits even on the basis of minimal observation in either trivial scenarios (e.g., Borkenau et al, 2004; Carney et al., 2007) or crafted trait-relevant situations (Hirschüller et al., 2015; McLarney-Vesotski et al., 2006).

While performance across perceivers tends to be fairly consistent in such studies, research yields much wider variability in the judgability of traits of different targets, raising the question of what makes a good or 'readable' target. A large number of factors have been proposed to contribute to target judgability (see Human \& Biesanz, 2013, for a review) with psychological adjustment being the most consistent predictor. Psychological adjustment may manifest as a particular configuration of Big 5 traits, including high $\mathrm{E}$, high $\mathrm{A}$, high $\mathrm{C}$ and low $\mathrm{N}$, a configuration which has been reported as particularly judgable (Colvin, 1993). 
Although this strand of research implies some targets may be easier to read overall, it does not tell us whether people differ in their judgments about people who score low or high as opposed to those who score in the average range of each trait individually. If the findings on target judgability hold across individual traits, this could suggest that perceivers will often be correct when judging a target as high E, high $\mathrm{A}$, high $\mathrm{C}$ and low N. On the other hand, research on trait judgments for samples that included individuals with known personality disorders, who by definition occupy extreme positions on various personality traits, found perceivers were able to accurately detect personality features of those disorders, implying that both extremes of traits may be distinctive and easy to detect (Oltmanns, Friedman, Fiedler, \& Turkheimer, 2004). Moreover, a recent study (Wu et al., 2016) revealed that perceivers tended to be correct when they judged a target as low or high empathy (measurable with the Empathy Quotient - EQ - Baron-Cohen \& Wheelwright, 2004) but not when they judged a target as average in empathizing. Examination of the pattern of responding reveals that perceivers tended to judge most targets as average in empathizing, making many 'false alarms' in doing so; in contrast, they were conservative but usually correct when judging targets as non-average in empathizing.

The present study aimed to explore if there is a similar pattern in people's ability to locate targets along the big-five personality dimensions: whether perceivers are typically correct when they judge someone as unique on a trait but less so (due to a high proportion of false alarms) when judging that someone is average. Adopting selfother agreement as the measurement of judgment accuracy, the current study asked 
the perceiver to detect each of the target's big-five traits on three levels (high, middle or low), allowing us to compare perceiver inferences against target self-reported traits measureable with the big-five personality inventory. Because traits give rise to fleeting patterns of behavior that transcend time and specific situations (Funder, 1991, 2006), we extracted 'thin slices' from ongoing behavior. The zero-acquaintance procedure was used to ensure that perceivers made judgments of big-five traits on the basis of the presented thin slices of behavior rather than any prior knowledge of the target. Considering its wide application and putative reliability and validity (Borkenau \& Ostendorf, 1998; McCrae \& John, 1992, for a review; McCrae \& Costa, 2004; McCrae, Terracciano, et al., 2005; Schmitt, Allik, McCrae, \& Benet-Martínez, 2007), this study employs the updated shortened version of the NEO Personality Inventory, the NEO Five-Factor Inventory-3 (NEO-FFI-3: McCrae \& Costa, 2004; Costa \& McCrae, 2011) to measure the targets' five dimensions of personality traits.

\section{Study 1}

\section{Method}

Three sets of video clips (with audio) were derived from a previous study (Wu, et al., 2016), with 47 clips in each set in which targets were recorded during a conversation, reading a joke or doing a screen test. We adopted a $5 \times 3 \times 3$ mixed design, with the big-five traits and the three levels of each trait (low, average, and high) as the within-subjects factors and the three scenarios (Conversation, Joke, and Screen Test) as the between-subjects factor. After viewing each video clip, perceivers 
needed to infer which level (low, average or high) on each of the big-five traits the target belonged to.

\section{Participants}

Ninety students (serving as perceivers) aged 18-25 years (45 males, $M=20$ years) were recruited from the University of Nottingham Malaysia campus. The sample size was determined according to our previous research (Wu et al., 2016). The perceivers were asked to identify whether they had met any of the targets after viewing pictures of them (taken from their videos) and those who responded positively were replaced. Each perceiver was randomly assigned to watch the targets either in the Conversation, in the Joke or in the Screen Test Scenario.

\section{Materials}

\section{Video stimuli collection and editing}

A Sony Handycam DCR-SR60 video camera filmed 47 targets (24 males, aged 18-32 years, $M=21$ years) recruited from the University of Nottingham Malaysia campus, all of whom responded to a call to do a screen test advertising the university. On arrival, targets were issued with a script of the joke and the screen test. All were individually videoed in a quiet laboratory with the camera mounted on a tripod placed approximately $1.2 \mathrm{~m}$ away to record the target's face and the top part of their body. The researcher sat opposite but out of view of the camera. Unknown to the target, the camera automatically began recording as soon as they entered the room.

(Subsequently, all targets were fully debriefed and gave written informed consent to use the videos for research purposes.) 
Once inside the laboratory, after the target read some information (including an information sheet, a script of the joke, a script of the screen test and a consent form), the researcher began with a brief conversation in which she asked a series of questions (and wrote down the responses) about the target's name, age, what course they were enrolled on, where they were from and so on. The conversation lasted approximately two minutes. The camera was then ostensibly switched to 'record mode' (note that it was already in record mode) and the target was invited to read out the joke to the camera. After a pause of about one minute the target was then invited to read aloud a verbatim script of the screen test:

"At the University of Nottingham we are committed to providing a truly international education, inspiring our students, producing world-leading research and benefitting the communities around our campuses in the UK, China and Malaysia. Our purpose is to improve life for individuals and societies worldwide. By bold innovation and excellence in all that we do, we make both knowledge and discoveries matter."

These three scenarios in which behavior was sampled were based upon those used in previous research on personality judgment demonstrating self-other agreement (e.g. Borkenau \& Liebler, 1992). We aimed to gain samples of both highly constrained behavior under known surveillance (joke and screen test) and less constrained behavior with covert video recording (conversation). Inclusion of three behavioral samples from each participant enabled us to determine the extent to which perceivers' judgments about a particular target were consistent across samples.

The NEO Five-Factor Inventory-3 (NEO-FFI-3) 
After recording and a short break for several minutes, each target completed the NEO-FFI-3, which is an updated and revised shortened version of the self-report form of the NEO Personality Inventory-3 (NEO-PI-R-3), with 12-item scales to measure each of the five personality factors, N, E, O, A, and C (McCrae \& Costa, 2004). The task took about 12 minutes and responses were collected on 5-point Likert scales ranging from strongly disagree to strongly agree.

We have defined $T$ scores within one standard deviation either side of the population mean as average, and scores above or below one standard deviation each side of the population mean as high or low respectively. In other words, $T$ scores of 61 or higher are considered high, $T$ scores ranging from 40 to 60 are considered average, and $T$ scores lower than 40 are considered low in each of the five trait domains. The targets' self-report ratings were thus classified into three levels of low, average or high: Eight (6 males), 26 (13 males) and 13 (5 males) targets respectively scored low, average and high on $\mathrm{N} ; 11$ (5 males), 26 (12 males) and 10 (7 males) were respectively low, average and high on E; 7 (6 males), 27 (13 males), and 13 (5 males) were low, average and high on O; 10 (7 males), 31 (14 males) and 6 (3 males) scored low, average and high on A; 14 (5 males), 24 (14 males) and 9 (5 males) were low, average and high on C (see Supplementary Materials S1 for analyses using a different criterion for defining the trait levels).

Three separate video clips were made for each target. In the Joke and the Screen Test Scenario, each clip began when the target started the task and ended about two seconds after the target completed reading the script. The average duration of the 
video clips was $30.87 \mathrm{~s}(S D=2.56$; ranging from $24 \mathrm{~s}$ to $35 \mathrm{~s})$ for the Conversation, $8.94 \mathrm{~s}(S D=1.36$; ranging from $7 \mathrm{~s}$ to $12 \mathrm{~s})$ for the Joke and $29.36 \mathrm{~s}$ for the Screen Test $(S D=4.48$; ranging from $22 \mathrm{~s}$ to $42 \mathrm{~s})$. Because the raw filming of the Conversation actually lasted around two minutes, we extracted 30-second clips from either the beginning (15 targets selected at random), the middle (16 targets selected at random) or the end (16 targets selected at random).

\section{Procedure}

Perceivers were tested individually. After receiving the instruction sheet and offering consent, the perceiver was given a personality information sheet that includes a brief definition of personality along with concise explanations of each personality trait in line with the description in the NEO manual (Costa \& McCrae, 2011):

“Personality traits are a person's characteristic patterns of thought, emotion and behavior that are relatively consistent over time and across situations (Funder, 2006); in other words, personality traits describe what a person is like. The following five factors are widely used to depict a person's basic personality traits.

Neuroticism: The tendency to experience unpleasant emotions easily, such as anxiety, depression, self-consciousness, impulsiveness and vulnerability. Extraversion: Warm, assertive (confident), active, sociable, excitement-seeking, and the tendency to experience positive emotions. Openness to Experience (Openness): Appreciation for art (and beauty), feelings and emotions, curiosity, unusual ideas, and variety of experience. Agreeableness: A tendency to be straightforward, altruistic (concern for others), compliant, modest, tender-minded. Conscientiousness: A 
tendency to show self-discipline, act dutifully, and aim for achievement; planned rather than spontaneous behavior; organized, and dependable."

After reading the personality information sheet, the perceiver proceeded to the trials of inferring the target's big-five traits. Each video clip was displayed $(600 \times 400$ pixels) to the perceiver in full color with audio in random order with the software PsychoPy (Peirce, 2007) on a laptop. Following each target video, a response screen appeared showing five 3-point scales (low, average \& high) as response options corresponding to the five traits of N, E, O, A, and C in fixed order. The perceiver used the mouse to click on one of three levels for each of the five traits for each target. After the perceiver made judgments for all five traits, the screen moved immediately to the next video clip. PsychoPy was programmed to allow perceivers to take as long as they needed to respond. Responses were automatically recorded by the software for later retrieval.

\section{Results and discussion}

\section{Preliminary analyses}

Three separate groups of perceivers rated the big-five traits of each of the 47 targets - one group rated the targets in conversation with the experimenter, another rated the targets as they told a joke and another rated the targets as they performed a screen test. Thus, each target had three mean ratings of scores for each of the five traits from perceivers who watched the target in a conversation, perceivers who watched the target tell a joke and perceivers who watched the target do a screen test. The intercorrelations between these three sets of ratings were high in each of the bigfive traits as shown in Table 1. Hence, irrespective of how accurate perceivers were in 
their inferences (see below), at least it seems that samples of target behavior across three scenarios led to rather consistent ratings of the big-five traits by the perceivers.

\section{Table 1 about here}

Two scores of each trait were coded for each target: their self-rated score of each trait $(\mathrm{N}: M=2.11, S D=.67 ; \mathrm{E}: M=1.98, S D=.68 ; \mathrm{O}: M=2.13, S D=65 ; \mathrm{A}: M=$ $1.91, S D=.58 ; \mathrm{C}: M=1.89, S D=.70)$ and their mean score as estimated by 90 perceivers (combined across three scenarios) for each trait $(\mathrm{N}: M=1.68, S D=.24$; $\mathrm{E}$ : $M=2.00, S D=.36 ; \mathrm{O}: M=1.98, S D=.31 ; \mathrm{A}: M=2.12, S D=.22 ; \mathrm{C}: M=2.07, S D$ $=.28$ ). There was a significant correlation between target self-ratings and perceiver ratings for Trait $\mathrm{E}: r=.32, p=.031$, but there were non-significant associations between target self-ratings and perceiver ratings for the other traits. This is only partially informative because it tells us nothing about whether big-five traits were judged differently at different levels of the scale. To illuminate such a matter, a different kind of analysis was adopted as explained below.

\section{Main analysis - Perceiver accuracy in detecting targets at three different levels of}

\section{each trait}

Any perceiver who judged the same category over $80 \%$ of the time across the five traits was removed from the following analyses in case such individuals were repeatedly picking the same category in order to complete the experiment rapidly, rather than making considered judgments. One male perceiver observing the Joke Scenario was duly excluded. 
Inspection of the data revealed that base rates in perceivers' judgments varied widely across the targets' three levels of each 'Big 5' trait. As shown in Table 2, it was common for perceivers to judge that targets were in the middle level but less common for them to judge that targets were in the two extreme levels in each condition. Because perceivers frequently judged targets to be in the middle level, in absolute terms 'correct' judgments were fairly common but this high frequency of correct judgments is at the cost of high frequency in false alarms.

\section{Table 2 about here}

Given that signal detection theory (SDT) allows an assessment of accuracy and sensitivity that is immune to response bias (the tendency to select one category more frequently than another; Macmillan, 2002; Macmillan \& Creelman, 2005; Stanislaw \& Todorov, 1999), it is widely applied to measure performance across various tasks, including those that employ multi-way forced choice procedures (Macmillan, 2002; Macmillan \&Creelman, 2005), as illustrated in the following examples: SDT has been used to examine accuracy in empathy judgments (Wu et al., 2016) and mental state inferences (Pillai et al., 2012, 2014), eyewitness's identification of suspects (Clark, 2012), perceptual judgments (Kang, Anthoney \& Mitchell, 2017), diagnostic decisions more generally (Swets, Dawes, \& Monahan, 2000) and optimal decision making (Lynn \& Barrett, 2014). We thus adopted SDT to compute participant accuracy (sensitivity) in detecting targets' trait levels.

According to the published guidelines on calculating SDT (Macmillan, 2002; Macmillan \& Creelman, 2005), a correct judgment that a target belonged to a 
particular level of each trait counted as a 'hit' while an incorrect judgment that a target belonged to the same trait level counted as a false alarm. Performance of participants across the different trait levels over a total of 47 trials was characterised as single values for each perceiver in the form of d-prime (d') for assessing perceiver accuracy in judging each trait level. Following Macmillan and Creelman (2005), where the perceiver either made no hits or no false alarms for a particular trait level, or where the number hits or false alarms was the maximum it could be for a trait level, these values were adjusted before calculating the hit rate and false alarm rate. Where the number of hits (or false alarms) was 0, 0.5 was added and the hit rate (or false alarm rate) was then calculated; where the participant made the maximum number of hits or false alarms for a given trait level, 0.5 was subtracted from the number of hits or false alarms prior to calculating the hit rate or false alarm rate. d' was then calculated by subtracting the z-score of the false alarm rate from the z-score of the hit rate $\left(\mathrm{d}^{\prime}=\mathrm{Z}\right.$ (hit rate) $-\mathrm{Z}$ (false alarm rate), where function $\left.\mathrm{Z}(p), 0 \leq p \leq 1\right)$. In addition, according to SDT outlined by Macmillan and Creelman (2005), we represent the base-rate as the 'criterion' (c) for choosing any particular response category with the statistic c: the more negative the value of $\mathrm{c}$, the more perceivers were in favour of choosing this particular category (e.g. a category of average E), irrespective of whether correct; but when $\mathrm{c}$ is more positive, it implies perceivers were against choosing the particular category (e.g. high or low E), meaning that they were conservative in this case. Criterion $\mathrm{c}$ was calculated by $-0.5 \mathrm{x}(\mathrm{Z}$ (false alarm rate $)+\mathrm{Z}$ (hit rate)). 
Table 3 shows the means of hit rate $\left(M_{H R}\right)$, false alarm rate $\left(M_{F A R}\right)$, d-prime $\left(M_{d^{\prime}}\right)$ and criterion $\left(M_{c}\right)$ in each level in each trait across the three scenarios combined, along with the $t$ values of one-sample $t$ tests of each $M_{d}$. As demonstrated in Table 3, the hit rates for the middle level of each trait were usually relatively high but the false alarm rates were also rather high; by contrast, in spite of relatively low hit rates for the two extreme levels, the corresponding false alarm rates were quite small. As a result, the d' (the index of perceiver sensitivity of detecting target traits), which was computed by comparing the proportion of hits against the proportion of false alarms, was low in the average trait level but high in the extremes. In other words, perceivers tended to judge the target was in the middle of the trait continuum though in many cases they were incorrect to do so when the target was actually located at the extremes; perceivers were less likely to judge the target was at the two extremes of the continuum but when they did so their judgments were frequently correct.

These results were confirmed by the one-sample $t$ tests of $M_{d}$, where the comparison value is zero: If perceivers were insensitive to when a target is in a particular trait level, this would yield an $M_{d}$, of zero for that level of the trait. According to the $t$ values displayed in Table 3, perceivers were not uniform in their judgments about big-five traits: When perceivers stated that a target was in the low and high levels, they tended to be correct (indicated by $M_{d}$ 'well above zero) while in all cases (except for $\mathrm{N}$ ) when they judged targets to be in the middle level of each trait they were often incorrect. Figure 1 demonstrates five similar trends associated with the five traits that reflect the pattern of $t$ test results. 
Table 3 \& Figure 1 about here

To examine perceivers' judgments of target trait levels, a 5 (traits) $\times 3$ (levels of each trait) $\times 3$ (scenarios) mixed design ANOVA was computed, with the 3 scenarios as the between-subjects factor, and the 5 traits and the 3 levels of each trait as the within-subjects factors; the dependent variable was the mean d'. Effect sizes are reported as Cohen's $f$, where $.10, .25$ and .40 respectively represent small, medium and large effect sizes (Cohen, 1988). A main effect was associated with the three trait levels $(F(2,172)=99.85, p<.001$, Cohen's $f=1.06)$, but there were no main effects associated with the five traits and the three scenarios. The interactions between Trait Level and Scenario $(F(4,172)=4.22, p=.003$, Cohen's $f=.21)$, between Trait and Level $(F(8,688)=12.59, p<.001$, Cohen's $f=.38)$, and an interaction among Trait, Level and Scenario $(F(16,688)=2.67, p=.003$, Cohen's $f=.17)$ were significant, but there was no interaction between Trait and Scenario.

To examine whether or not perceivers were more likely to be correct when they judged that targets were located in the two extreme levels of each trait than when they judged that targets were located in the middle level (shown in the results of onesample $t$ tests in Table 3 and demonstrated in Figure 1), we conducted a repeated measures ANOVA for each trait across the three scenarios combined, with the three trait levels as the within-subjects factor. The results showed that $M_{d}$, among the three levels of each trait were significantly different in all cases $(\mathrm{N}: F(2,176)=6.67, p$ $=.002$, Cohen's $f=.27 ; \mathrm{E}: F(2,176)=94.78, p<.001$, Cohen's $f=1.03 ; \mathrm{O}: F(2$, $176)=21.71, p<.001$, Cohen's $f=.49 ; \mathrm{A}: F(2,176)=10.64, p<.001$, Cohen's $f$ 
$=.35 ; \mathrm{C}: F(2,176)=13.16, p<.001$, Cohen's $f=.38)$. Post hoc Bonferroni-adjusted tests for each trait revealed the following results. For the trait N, perceivers were less often correct when judging targets as average $\mathrm{N}$ than when judging targets as either low $\mathrm{N}(p<.001)$ or high $\mathrm{N}(p=.048)$, but there was no difference when they judged cases as low and high N. For the trait E, perceivers were more often correct when they judged a target as high in $\mathrm{E}$ than when they judged targets to fall into either low $\mathrm{E}$ or average $\mathrm{E}(p s<.001)$, and they also were more often correct when they judged targets as low $\mathrm{E}$ than when they judged targets as average $\mathrm{E}(p=.009)$. For the trait $\mathrm{O}$, perceivers were often correct when they judged targets to be either low or high O, but they were less often correct when they judged a target as average $\mathrm{O}(p s<.001)$. For the trait A, perceivers were more often correct when they judged a target to be either low or high in A than when they judged targets to be average A $(p s<.001)$, but were equally often correct when they judged a target to be low or high A. For the trait C, perceivers were more often correct when they judged targets as being high $\mathrm{C}$ in comparison with when they judged a target as low $(p=.005)$ or average $\mathrm{C}(p<.001)$, and performance was no different when they judged a target as low or average C.

To examine whether the criterion differed for judging targets as low, average and high, a 5 (traits) $\times 3$ (levels of each trait) $\times 3$ (scenarios) mixed design ANOVA was computed, with the 3 scenarios as the between-subjects factor, and the 5 traits and the 3 levels of each trait as the within-subjects factors; the dependent variable was the mean c. There was a main effect of trait, $F(4,344)=18.03, p<.001$, Cohen's $f=.46$, a main effect of level, $F(2,172)=127.49, p<.001$, Cohen's $f=1.21$, and a main 
effect of scenario, $F(2,86)=3.21, p=.045$, Cohen's $f=.27$. The interactions between Trait and Scenario $(F(8,344)=2.12, p=.041$ (Greenhouse-Geisser corrected), Cohen's $f=.22)$, between Trait and Level $(F(8,688)=25.98, p<.001$, Cohen's $f=.55)$, and an interaction among Trait, Level and Scenario $(F(16,688)=$ $3.13, p<.001$, Cohen's $f=.27$ ) were significant, but there was no interaction between Trait Level and Scenario.

To examine whether or not perceivers differed in the criterion they adopted for the two extreme levels of each trait than for the middle level (as shown in Table 3), we conducted a repeated measures ANOVA for each trait across the three scenarios combined, with the three trait levels as the within-subjects factor. The results showed that $M_{c}$ among the three levels of each trait were significantly different in all cases $(\mathrm{N}$ : $F(2,176)=51.45, p<.001$, Cohen's $f=.76 ; \mathrm{E}: F(2,176)=44.91, p<.001$, Cohen's $f=.71 ; \mathrm{O}: F(2,176)=53.40, p<.001$, Cohen's $f=.78 ; \mathrm{A}: F(2,176)=114.52, p$ $<.001$, Cohen's $f=1.14$; C: $F(2,176)=99.65, p<.001$, Cohen's $f=1.06)$. Post hoc Bonferroni-adjusted tests for each trait revealed the following results. For the trait N, perceivers were more conservative when judging targets as high $\mathrm{N}$ than when judging targets as either low $\mathrm{N}$ or average $\mathrm{N}(p s<.001)$, but were equally conservative when they judged cases as low $\mathrm{N}$ and average $\mathrm{N}$. For the trait $\mathrm{E}$, perceivers were more conservative in judging a target as high or low $\mathrm{E}$ than average $\mathrm{E}(p s<.001)$, but were equally conservative in judging targets as low and high E. For the trait O, perceivers were more conservative in judging targets as high $\mathrm{O}$ than average or low $\mathrm{O}$ (ps $<.001$ ), and they were also more conservative in judging a target as low than average 
$\mathrm{O}(p<.001)$. For the trait A, perceivers were more conservative when judging a target as low or high in $\mathrm{A}$ than as average $\mathrm{A}(p s<.001)$, but were equally conservative in judging a target to be low or high $\mathrm{A}$. For the trait $\mathrm{C}$, perceivers were more conservative in judging targets as low $\mathrm{C}$ in comparison with high or average $\mathrm{C}$ ( $p s$ $<.001$ ), and they were also more conservative in judging targets as high $\mathrm{C}$ than judging them as average $(p<.001)$. See Supplementary Materials $(\mathrm{S} 2)$ for analysis using an alternative way of operationalising criterion.

Is it possible that the trends of perceivers' performance in detecting targets with different levels of traits shown in Figure 1 are an artifact of a 'range effect'? The dependent variable d' represented the z-score for the proportion of hits (for example that judging the target was in the category of low $\mathrm{N}$ and he/she was truly located on low $\mathrm{N}$ ) minus the z-score for the proportion of false alarm (such as judging that the target was in low $\mathrm{N}$ when in fact he/she was in the level of average or high). For average targets, all opportunities for false alarms arose in adjacent categories (low or high) while for low or high targets, some opportunities for false alarms arose from an adjacent category (average) and some from a more distal category (high or low, respectively). Arguably a perceiver may be less likely to make a false alarm in a distal than adjacent category for a particular target, so the inclusion of false alarms from distal categories in the false alarm rate for d-prime calculations for targets in the high and low category could have resulted in lower overall false alarm rates. This could artifactually lead to the value of $M_{d}$, being lower for the middle level than for the outer levels, thus giving rise to a spurious trend in which perceivers seemed to perform better when inferring 
that a target is located in the two extreme levels than when inferring that a target is in the middle.

We addressed this matter by statistically adjusting the false alarm rates and then repeating all the analyses (see the Supplementary Materials S3 for the results). The false alarm rate of judgments on each trait level was confined to cases where correct responses would have been the neighboring level of the same trait (or the number of times the correct response would have been one or other of the two neighboring levels of the trait in the average level). The same trends emerged even with these adjusted false alarm rates (as shown in Table S3 \& Figure S3). This was true not only in the current study but also in Studies 2 and 3 reported in this article. It seems, then, that perceivers tended to be incorrect when they judged targets as being average in each of the big-five traits but tended to be correct when they judged a target to be extreme.

\section{Study 2}

Study 1 revealed that when perceivers identified a target as being at the end point of each trait continuum they tended to be correct across the three scenarios from watching videos with audio; perceivers were not systematically correct when they identified a target as average. Given that predicting and explaining behavior is normally done rapidly in a context of fleeting information, we also aimed to discover how little information is sufficient for making this pattern of inferences of big-five traits. The purpose of Study 2 was to explore the limitation in perceiver ability to detect target personality traits. Specifically, would the principal findings reported in Study 1 be replicated with different types of information channels (video with audio, 
silent video, and soundtrack only)? For the sake of simplicity the present study only used the scenario of Conversation where the targets were unobtrusively filmed while answering some questions about themselves - This scenario might evoke informative spontaneous behaviors in the targets.

\section{Method}

\section{Participants}

Ninety students (43 males) aged 18-27 years $(M=21$ years) from the Monash University Sunway campus were recruited as perceivers. None reported acquaintance with any of the targets. The sample size was determined according to our previous research (Wu et al., 2016). Perceivers were randomly assigned to three groups of 30 in each condition (Video with audio, Video only, and Audio only).

\section{Materials and Procedure}

The 47 video clips in the Conversation Scenario were used with or without audio. The 47 audio tracks were extracted from the corresponding video clips. Thus, 30 perceivers viewed 47 video clips with audio, 30 perceivers viewed the same 47 clips without sound, and 30 perceivers listened to 47 audio tracks. The procedure was the same as that in Study 1. After watching a video with audio or a silent video or hearing a soundtrack, perceivers were asked to infer the big-five traits of each target.

\section{Results and discussion}

\section{Judgmental accuracy of the big-five traits in each condition}

As in Study 1, any perceiver who judged the same category over $80 \%$ of the time across the five traits was removed from the following analyses. One female in the 
video with audio condition and one female in the audio only condition were duly excluded. Table 4 shows $M_{H R}, M_{F A R}$, and $M_{c}$ in each level of each trait in each information condition, together with the corresponding values of one-sample $t$ tests of each $M_{d}$. As we see in Table 4 and Figures $2-4$, perceivers seemed to demonstrate a similar trend to Study 1 in their judgments of the big-five traits in each condition. When they judged a target as having an average level of the trait, perceivers usually did not perform above chance (except for the average level of trait $\mathrm{O}$ in the Audio Only condition), but they tended to be correct when identifying a target as being either low or high in one or more traits in each condition. Furthermore, this pattern of performance seemed to be influenced by information conditions - The trends seemed strongest in the condition of video with audio where perceivers tended to be correct when judging extreme trait levels in more types of traits than in the other information conditions; also, the trend appeared to be more evident in some traits, such as $\mathrm{O}$, than others, such as A, across the three conditions.

\section{Table 4 \& Figure 2-4 about here}

We conducted a 5 (traits) $\times 3$ (levels of each trait) $\times 3$ (conditions) mixed design ANOVA, with the five traits and the three levels of each trait as the within-subjects factors and the three conditions as the between-subjects factor; the dependent variable was $M_{d}$. The results revealed main effects associated with the traits $(F(4,340)=$ $4.41, p=.002$, Cohen's $f=.22)$, the trait levels $(F(2,170)=104.93, p<.001$, Cohen's $f=1.09)$, and the conditions $(F(2,85)=4.92, p=.009$, Cohen's $f=.24)$; additionally, there were interactions between the trait levels and the conditions ( $F$ (4, 
$170)=4.10, p=.003$, Cohen's $f=.22)$, between the traits and the levels of trait $(F(8$, $680)=7.08, p<.001$, Cohen's $f=. .28$ ), and an interaction among the traits, the trait levels and the conditions $(F(16,680)=2.54, p=.001$, Cohen's $f=.17)$, but there was no interaction between the traits and the conditions.

We carried out post hoc Bonferroni-adjusted tests for the main effect of condition, and found that overall perceivers performed equally well in the video with audio condition and the audio only condition, and perceiver performance in the video with audio condition was better than that in the video only condition $(p=.008)$. These data suggest that perceivers were generally more effective in inferring personality traits with access to both visual and auditory information of the targets for thirty seconds than when they had access only to visual information.

To examine whether there was a similar type of trend for each condition, we carried out a 5 (traits) $\times 3$ (trait levels) repeated measures ANOVA in each condition. As demonstrated in Table 5, which reports the corresponding results of the ANOVA in the three conditions, the same kind of trend emerged in each condition - there was a main effect of trait levels and a significant interaction between the traits and the levels but no main effect associated with the traits. Additionally, the interaction between the traits and the trait levels was strongest in the video with audio condition.

\section{Table 5 about here}

To examine whether there were differences in criterion for judging targets as low, average and high, a 5 (traits) $\times 3$ (levels of each trait) $\times 3$ (conditions) mixed design ANOVA was computed, with the 3 conditions as the between-subjects factor, and the 
5 traits and the 3 levels of each trait as the within-subjects factors; the dependent variable was $M_{c}$. There was a main effect of trait $(F(4,340)=11.15, p<.001$, Cohen's $f=.36)$ and a main effect of trait level $(F(2,170)=91.58, p<.001$, Cohen's $f=1.02)$ but no main effect of condition. The interaction between Trait and Level ( $F$ $(8,680)=25.76, p<.001$, Cohen's $f=.54)$ and an interaction among Trait, Level and Condition $(F(16,680)=1.74, p=.036$, Cohen's $f=.14)$ were significant, but there were no interactions between Trait Level and Condition, or between Trait and Condition.

To examine whether or not perceivers differed in the criterion they adopted for the two extreme levels of each trait than for the middle level (as shown in Table 4), we conducted a repeated measures ANOVA for each trait across the three conditions combined, with the three trait levels as the within-subjects factor. The results showed that $M c$ among the three levels of each trait were significantly different in all cases $(\mathrm{N}: F(2,174)=49.15, p<.001$, Cohen's $f=.74 ; \mathrm{E}: F(2,174)=44.64, p<.001$, Cohen's $f=.71 ;$ O: $F(2,174)=40.78, p<.001$, Cohen's $f=.68 ; \mathrm{A}: F(2,174)=$ 79.29, $p<.001$, Cohen's $f=.95 ; \mathrm{C}: F(2,174)=77.17, p<.001$, Cohen's $f=.94)$. Bonferroni-adjusted post hoc tests for each trait revealed the following results. For the trait $\mathrm{N}$, perceivers were more conservative when judging targets as high $\mathrm{N}$ than when judging targets as either low $\mathrm{N}$ or average $\mathrm{N}(p s<.001)$, but were equally conservative when they judged cases as low $\mathrm{N}$ and average $\mathrm{N}$. For the trait $\mathrm{E}$, perceivers were more conservative in judging a target as high or low $\mathrm{E}$ than average $\mathrm{E}$ ( $p s<.001)$, but were equally conservative in judging targets as low and high E. For 
the trait $\mathrm{O}$, perceivers were more conservative in judging targets as high $\mathrm{O}$ or low $\mathrm{O}$ than average $\mathrm{O}(p s<.001)$, and they were equally conservative in judging a target as low and average $\mathrm{O}$. For the trait $\mathrm{A}$, perceivers were more conservative when judging a target as low in A than targets as either average or high $\mathrm{A}(p s<.001)$, and they were also more conservative in judging a target to be high $\mathrm{A}$ than average $\mathrm{A}(p<.001)$. For the trait $\mathrm{C}$, perceivers were more conservative in judging targets as low $\mathrm{C}$ in comparison with high or average $\mathrm{C}(p s<.005)$, and they were also more conservative in judging targets as high $\mathrm{C}$ than judging them as average $(p<.001)$.

\section{The trends in judgmental accuracy in each trait in each condition}

\section{Video with audio condition}

From Study 1 we already know that perceivers frequently made correct judgments about the big-five traits based on a series of videos with audio across different scenarios, and perceivers were more likely to be correct when they judged a target as having a high or low level of a trait than when they judged a target was average. Would these findings be replicated with the Conversation Scenario only?

Table 4 and Figure 2 show that, as with Study 1, perceivers did not uniformly make correct judgments of each level of each trait: perceivers tended to be correct when they judged a target as low N, high E, low and high O, high A as well as high $\mathrm{C}$, but there was no evidence of perceivers being correct when they judged a target was in the middle of each trait.

A repeated measures ANOVA was conducted for each trait, with the three trait levels as the within-subjects factor. The results revealed that the means of d' across 
the three levels of each trait (except for $\mathrm{N})$ were significantly different $(\mathrm{N}: F(2,56)$ $=.87, p=.427 ; \mathrm{E}: F(2,56)=60.94, p<.001$, Cohen's $f=1.45 ; \mathrm{O}: F(2,56)=4.83, p$ $=.012$, Cohen's $f=.41 ; \mathrm{A}: F(2,56)=8.52, p=.001$, Cohen's $f=.54 ; \mathrm{C}: F(2,56)=$ 18.69, $p<.001$, Cohen's $f=.80$ ). Post hoc Bonferroni-adjusted tests for each trait (except for $\mathrm{N}$ ) revealed the following results. For the trait E, perceivers were more often correct when they judged a target as high E than when they judged a target as being low E or average $\mathrm{E}(p s<.001)$, and they performed similarly when they judged the targets as low $\mathrm{E}$ or average $\mathrm{E}$. For the trait $\mathrm{O}$, perceivers were more often correct when they judged a target as low $\mathrm{O}(p=.038)$ and high $\mathrm{O}(p=.001)$ than when they judged a target as average $\mathrm{O}$, but performance in detecting targets as low or high $\mathrm{O}$ was not significantly different. For the trait A, perceivers were less often correct when they identified a target as average A than when they identified a target as low ( $p$ $=.01)$ or high $(p=.001)$ in A, but there was no difference when they identified a target as low or high A. For the trait C, perceivers were more often correct when they identified the targets as high than when they identified the target as low and average $(p s<.005)$, and they performed similarly when identifying targets as low and average C.

Overall, perceivers' performance in detecting the big-five traits in the video with audio condition replicated similar trends found in Study 1 with a small exception. It seems perceiver performance when making judgments about high and low levels on some traits (e.g., the trait of N) was stronger in Study 1 than in Study 2, which might 
be because the current study was based only on the Conversation Scenario whereas

Study 1 calculated the aggregate accuracy across the three scenarios.

\section{Video only condition}

Would the findings in the video with audio condition generalize to the video only condition? According to Table 4 and Figure 3, perceivers were often correct when they judged that targets had high $\mathrm{N}$, high $\mathrm{E}$, low and high $\mathrm{O}$, as well as high $\mathrm{C}$ while viewing a silent video. A repeated measures ANOVA was conducted for each trait, with the three trait levels as the within-subjects factor. The results revealed that the means of d' across the three levels of each trait were significantly different except for the trait $\mathrm{A}(\mathrm{N}: F(2,58)=4.07, p=.022$, Cohen's $f=.37 ; \mathrm{E}: F(2,58)=22.57, p$ $<.001$, Cohen's $f=.96 ;$ O: $F(2,58)=4.52, p=.015$, Cohen's $f=.39 ; \mathrm{A}: F(2,58)=$ $1.61, p=.210 ; \mathrm{C}: F(2,58)=5.31, p=.008$, Cohen's $f=.42)$. Post hoc Bonferroniadjusted analyses for each trait (except for A) revealed the following things. For trait $\mathrm{N}$, perceivers were more often correct when they judged a target as high $\mathrm{N}$ than as average $\mathrm{N}(p=.002)$. For the trait $\mathrm{E}$, perceivers were more often correct when they judged a target as high $\mathrm{E}$ than as either low or average $\mathrm{E}(p s<.001)$, and they performed equally well when they judged targets as low or average in E. For the trait $\mathrm{O}$, perceivers were more effective when they judged targets as high $\mathrm{O}$ than when they judged targets as average $\mathrm{O}(p=.026)$. For the trait $\mathrm{C}$, perceivers were only more often correct when they identified targets as high $\mathrm{C}$ than when they judged targets as average $\mathrm{C}(p=.017)$. 
In summary, while observing the targets having a conversation with sound muted perceivers were often correct when they judged a target as being located in the extremes of most big-five trait continua. They generally tended to be more often correct when they judged targets as either low or high on some trait continua than when they judged targets as being in the middle level of the traits.

\section{Audio only condition}

As shown in Table 4 and Figure 4, perceivers were seldom correct when they judged targets at any level of $\mathrm{C}$, but they were effective when identifying the targets as being in each level of $\mathrm{O}$, and they also tended to be correct when they identified targets as high $\mathrm{N}$, low and high $\mathrm{E}$ as well as low and high $\mathrm{A}$. They were not systematically correct when judging targets as being in the middle level of each trait (except for O). A repeated measures ANOVA was conducted for each trait, with the three levels as the within-subjects factor. The results showed that the mean d'values across the levels of each trait were significant except for the traits $\mathrm{O}$ and $\mathrm{C}(\mathrm{N}: F(2$, $56)=4.54, p=.015$, Cohen's $f=.40 ; \mathrm{E}: F(2,56)=9.49, p<.001$, Cohen's $f=.57$; $\mathrm{O}: F(2,56)=.49, p=.62 ; \mathrm{A}: F(2,56)=18.82, p<.001$, Cohen's $f=.81 ; \mathrm{C}: F(2$ $56)=.68, p=.512$ ). The results of post hoc Bonferroni-adjusted tests for the traits $\mathrm{N}$, $\mathrm{E}$ and $\mathrm{A}$ were as follows. For the trait N, perceivers were equally correct when they judged targets as having low and high $\mathrm{N}$, and the performance in both cases was better than when they judged targets as having average $\mathrm{N}(p s \leq .036)$. For the trait $\mathrm{E}$, perceivers tended to be more often correct when they identified targets as low ( $p$ $=.025)$ and high $\mathrm{E}(p<.001)$ than when they identified targets as average $\mathrm{E}$, and the 
performance when judging targets as low and high E was not different. For the trait A, perceivers were more often correct when they judged targets as low $(p=.002)$ and high A $(p<.001)$ than when they judged targets as average A; they were similarly effective when judging cases as low and high A.

To summarize, in the Audio only condition, when judging N, E and A, perceivers were not systematically correct when they judged targets as being in the average level; but they tended to be correct when judging targets as either high or low in trait levels (or both), and their performance when judging targets as being in these outer levels was significantly better in most cases compared with when they judged targets as being in the average level.

\section{Study 3}

The previous two studies conducted in Malaysia demonstrated that perceivers seemed to perform better when identifying targets as having low or high levels of traits than when they identified them as average. Could this finding be replicated in another context with a different population? Study 3 was conducted in a different cultural context with the aim of investigating whether perceivers' detection of levels of traits of unfamiliar targets forms a similar pattern to that reported in Studies 1 and 2.

\section{Method}

\section{Participants}

Thirty-nine participants (perceivers; 18 males) aged 20-47 years $(M=25.74$ years, $S D=6.38$ ) were recruited from the University of Nottingham UK campus. The 
sample size was determined according to our previous research (Wu et al., 2016). The perceivers were asked to identify whether they had met any of the targets (after viewing the videos) and any who responded positively were excluded from the analysis.

\section{Materials}

Video stimuli \& the NEO Five-Factor Inventory-3 (NEO-FFI-3)

Forty-eight participants (targets; 19 males) aged 18 -34 years $(M=23.73$ years, $S D=3.58)$ were recruited from the University of Nottingham UK campus. Each target's face and the top part of their body was recorded while they were reading the verbatim script of a joke to the camera. The mean length of the videos was $12.19 \mathrm{~s}$ $(S D=1.53$, ranging from $7.98 \mathrm{~s}$ to $16.18 \mathrm{~s})$.

After recording and a short break, each target completed the NEO-FFI-3. As in the previous studies, targets' self-report ratings were classified into levels of Low, Average or High: Three (3 males), 31 (15 males) and 14 (1 male) targets respectively scored low, average and high on N; 5 (2 males), 27 (4 males) and 16 (13 males) were respectively low, average and high on E; 1 (0 males), 27 (9 males), and 20 (10 males) were low, average and high on O; 7 (4 males), 29 (12 males) and 12 (3 males) scored low, average and high on A; 11 (5 males), 32 (13 males) and 5 (1 male) were low, average and high on $\mathrm{C}$.

\section{Procedure}

The procedure was based upon what we had developed for Studies 1 and 2. After reading the personality information sheet, perceivers were instructed to do the trait 
judgment task presented on a computer using PsychoPy. Perceivers had to detect which trait level (high, average or low) of each of the five traits the target belonged to as they viewed each video clip.

\section{Results and discussion}

\section{Main analysis - Detecting the big-five traits of the target}

Preliminary checks showed that no perceivers judged the same category over $80 \%$ of the time across the five traits so all perceivers were retained in the analysis. Table 6 shows the means of hit rate $\left(M_{H R}\right)$, false alarm rate $\left(M_{F A R}\right)$, d-prime $\left(M_{d^{\prime}}\right)$ and criterion $\mathrm{c}\left(M_{c}\right)$ in each category of each trait, along with the values of one-sample $t$ tests for each $M_{d}$. There was a small amount of missing data where the perceiver either failed to give a response for one trait or in some cases the program malfunctioned. To maximize statistical power, we retained perceivers with a small amount of missing data $(<15 \%)$, adjusting the hit rate and false alarm rate to be calculated only across the trials the perceiver actually responded to. For example, if the perceiver correctly identified 4 out of 10 targets with low E but did not make a response for two of the low E targets, the hit rate would be $4 / 8$ or 0.5 . The false alarm rate for average and high $\mathrm{E}$ targets would also be adjusted in this example, because there would be fewer opportunities for a false alarm for such cases.

As demonstrated in Table 6 and Figure 5, perceivers were not uniformly effective in detecting each trait and each level of each trait. After observing the target reading a brief joke, perceivers were often incorrect when they identified targets as being in the 
average level of the trait continuum, but tended to be correct when they judged cases as low $\mathrm{N}$, low and high $\mathrm{E}, \mathrm{O}$ and $\mathrm{C}$, as well as low $\mathrm{A}$.

\section{Table 6 about \& Figure 5 here}

To examine whether the perceivers differed across the three trait levels and the five traits, a 5 (traits) $\times 3$ (trait levels) repeated-measures ANOVA was computed, with the 5 traits and the 3 levels of each trait as the within-subjects factors; the dependent variable was $M_{d}$. There were main effects associated with the five traits ( $F$ $(4,152)=5.64, p=.001$, Cohen's $f=.38)$ and the three trait levels $(F(2,76)=53.49$, $p<.001$, Cohen's $f=1.19)$ as well as an interaction between Trait and Level $(F(8$, 304) $=3.18, p<.01$, Cohen's $f=.29)$.

To examine how perceivers' judgments differed at different trait levels, we conducted a repeated measures ANOVA for each trait, with the three trait levels as the within-subjects factor. The results showed that $M_{d}$ 'values among the three levels of each trait were significantly different in all cases $(\mathrm{N}: F(2,76)=5.69, p<.01$, Cohen's $f=.39 ; \mathrm{E}: F(2,76)=7.35, p<.005$, Cohen's $f=.44 ; \mathrm{O}: F(2,76)=31.24, p$ $<.001$, Cohen's $f=.91 ;$ A: $F(2,76)=10.02, p<.005$, Cohen's $f=.51 ; \mathrm{C}: F(2,76)=$ 4.46, $p<.05$, Cohen's $f=.34)$. Post hoc Bonferroni-adjusted tests for the three levels of each trait revealed the following results. For the trait N, perceivers were more often correct when they judged targets as low $\mathrm{N}$ than when they judged targets as average $\mathrm{N}$ $(p=.002)$. For the trait E, perceivers were more often correct when they identified targets as low $\mathrm{E}$ than when they identified targets as average $\mathrm{E}(p=.004)$, and perceivers were more often correct when they identified targets as high E than as 
average $\mathrm{E}(p=.034)$. For the trait $\mathrm{O}$, perceivers were more often correct when they identified targets as low $\mathrm{O}$ than as average and high $\mathrm{O}(p s<.001)$ and they were also more often correct when they judged targets as high $\mathrm{O}$ than average $\mathrm{O}(p<.001)$. For the trait A, perceivers were more effective when they judged targets as low A or high A than as average $(p s \leq .001)$. For trait $\mathrm{C}$, perceivers were more often correct when they identified targets as low $\mathrm{C}$ than as average $\mathrm{C}(p=.035)$ and they were also more often correct when they identified targets as high $\mathrm{C}$ than average $\mathrm{C}(p=.020)$.

In order to determine whether or not perceivers differed in the criterion they adopted for the two extreme levels of each trait than for the middle level (shown in Table 6), we conducted a repeated measures ANOVA for each trait, with the three trait levels as the within-subjects factor. The results showed that $M_{c}$ for the three levels of each trait was significantly different in all cases $(\mathrm{N}: F(2,76)=43.46, p$ $<.001$, Cohen's $f=1.07$; E: $F(2,76)=34.99, p<.001$, Cohen's $f=.96 ;$ O: $F(2,76)$ $=52.22, p<.001$, Cohen's $f=1.17 ; \mathrm{A}: F(2,76)=96.18, p<.001$, Cohen's $f=1.59$; C: $F(2,76)=131.45, p<.001$, Cohen's $f=1.86)$. Post hoc Bonferroni-adjusted tests for each trait revealed the following results. For the trait N, perceivers were more conservative when judging targets as high $\mathrm{N}$ than when judging targets as either low $\mathrm{N}$ or average $\mathrm{N}(p s<.001)$, but were equally conservative when they judged cases as low $\mathrm{N}$ and average $\mathrm{N}$. For the trait $\mathrm{E}$, perceivers were more conservative in judging a target as high or low E than average $\mathrm{E}(p s<.001)$, and were more conservative in judging targets as high than low $\mathrm{E}(p<.01)$. For the trait $\mathrm{O}$, perceivers were more conservative in judging targets as high $\mathrm{O}$ than average or low $\mathrm{O}(p s<.001)$, and they 
were also more conservative in judging a target as low than average $\mathrm{O}(p<.001)$. For the trait A, perceivers were more conservative when judging a target as low than average or high in A ( $p s<.001)$, and were more conservative in judging a target to be high than average $\mathrm{A}$. For the trait $\mathrm{C}$, perceivers were more conservative in judging targets as being low $\mathrm{C}$ in comparison with high or average $\mathrm{C}(p s<.001)$, and they were also more conservative in judging targets as high $\mathrm{C}$ than judging them as average $(p<.001)$.

In summary, based on a sample of targets and perceivers recruited from a different culture, Study 3 suggested the following results: (1) perceivers were unsuccessful when they identified targets as being in the middle level of each dimension of the big-five traits; (2) when perceivers judged targets as being low $\mathrm{N}$, low and high E, O, and C, as well as low A they tended to be correct, and more so than when they judged targets as being in the middle level of the traits.

\section{General Discussion}

In Study 1, after watching a short video with audio across the three scenarios, perceivers tended to be correct when judging that a target was high or low in each trait but performed less well when they judged targets as average. Based on the videos with audio in the Conversation Scenario, Study 2 replicated these findings to a large degree: Perceivers tended to be correct when they identified targets as scoring either low or high on $\mathrm{O}$, and low in $\mathrm{N}$, high in traits $\mathrm{E}, \mathrm{A}$ and $\mathrm{C}$. With a sample of targets and perceivers recruited from the UK, Study 3 also found perceivers tended to be correct when they judged targets as low in $\mathrm{N}$, low or high in $\mathrm{E}$, low or high in $\mathrm{O}$, low 
in A and low or high in C; and they were generally not effective when judging targets as within the average level of each trait.

Previous research suggests that people are capable of making accurate judgments about some dimensions of the big-five traits (e.g., Albright et al., 1988; Borkenau \& Liebler, 1992, 1993; Borkenau et al., 2004; Carnet et al., 2007; McLarney-Vesotski et al., 2006; Watson, 1989) and can detect the distinctive from the normal in terms of general personality profiles (Biesanz \& Human, 2010). The present study has extended these findings by showing that when people judge targets as being at the outer levels (high or low) of the big five personality continua they tend to be correct, while this is not the case when they judge targets to be in the middle. A similar pattern of performance was found in a previous study which reported the ability to infer targets' trait of empathy (Wu et al., 2016).

Taken together, the findings here suggest that the strategy (or bias or preference) of perceivers was to judge most people as average unless their behavior suggests otherwise. This may be fairly effective in that it leads to a high frequency of correct identifications overall, given that most people do fall within the category of average. Nevertheless, when perceivers judged that a target fell into one of the two extreme levels of a trait, they tended to be correct. Moreover, perceivers adopted a conservative criterion for judging targets as being extreme - they frequently judge that targets are average but judge that targets are in the extremes infrequently. However, when they do make a judgment in one of the extremes it is often correct, implying that people with high or low levels of traits may sometimes stand out from the crowd. 
One explanation we explore concerns the strength of the signal that is available to perceivers: Compared with the average, targets who are high or low in personality traits might behave in ways that are atypical (and do not typically follow situational norms); for instance, an extravert is more talkative than normal while an introvert is rather quieter than normal during social interactions. The behavior of targets located in the middle of trait continua perhaps does not stand out from 'normal' behavior behavior that is normal for that particular situation. Perhaps perceivers assume that targets are average unless there is a clear signal that suggests otherwise, resulting in a subset of those who fell into the extremes of each trait being identified as such, with everyone else assumed to be average. This possibility is also consistent with the finding that there was variability between the traits in the exact pattern of performance. This may be because some traits have a stronger signal at high than low levels, and for others vice versa. In other words, there may be clearer, more visible behavioral cues signaling at one end of the trait distribution than the other.

Another possibility is that people are better adapted to identify those with high or low trait levels because these levels are more evaluative than middle levels. Typically, one end of each trait dimension can be seen as desirable (such as high A or high C) while the other end might be regarded as undesirable (such as low A, high $\mathrm{N}$ ), and it may be particularly advantageous to be able to identify others who have highly desirable or undesirable traits, to decide who to cooperate with and who to avoid. Previous research has suggested lower self-other agreement for traits that are more evaluative (for example, conscientiousness is more evaluative than extraversion), 
perhaps due to inaccuracies in self-reports of evaluative traits (John \& Robins, 1993). However, previous research has not addressed the possibility that scores within particular trait dimensions can be more or less evaluative.

It is possible that processes combine in making high and low levels of traits detectable in some targets; the mechanisms discussed above are not mutually incompatible. For instance, the desirability of a trait might impact on the strength of the signal as targets make greater efforts to mask traits at the undesirable end of the trait continuum. This could also explain some of the variability between traits: high $\mathrm{N}$ was less well-identified across studies than low $\mathrm{N}$, which could be due to targets producing less clear signals of this trait level. While it is perhaps adaptive to be able to identify those with atypical standing on a particular trait, it might also be adaptive in some cases for targets to conceal such trait levels. Study 3 replicated the general pattern of results of Studies 1 and 2 - after watching the target tell a joke, perceivers tended to be correct when they judged a target as low N, low and high E, low and high $\mathrm{O}$, low A, and low and high $\mathrm{C}$. The similarity is striking given that the studies recruited samples of targets from culturally different populations performing slightly different tasks. Studies 1 and 2 were conducted in Malaysia and sampled a wider range of target behavior, such as having a conversation, telling a joke and reading promotional material. In contrast, Study 3 was conducted in the UK and was based only on targets telling a (different) joke. Even so, perceivers were inclined to be correct when they identified targets as having the higher and lower levels of traits but not when they judged targets as having an average level of the big-five traits. 
Finally, it is worth considering the findings here in the context of other research on individual differences in target judgability. Colvin (1993) reported that targets with high $\mathrm{E}$, high $\mathrm{A}$, high $\mathrm{C}$ and low $\mathrm{N}$ are particularly easy to judge, and more recently Wood, Gosling and Potter (2007) found that a similar configuration of traits tended to be perceived as 'normal' as opposed to 'unique'. Taken together, the above findings contrast with the current research in implying that targets who seem particularly 'normal' are easy to judge. Nevertheless, the results may not be inconsistent. In the study by Wood et al., it was shown that what is perceived as normal is not necessarily the same as the 'true' average standing on the traits. Moreover, the results in Study 1, Study 2 (Video with Audio condition) and Study 3 were somewhat consistent with the pattern observed by Colvin (where perceivers tended to be correct when they judged a target as high E, high A, high $\mathrm{C}$ and low N). Furthermore, here the focus was on individual traits rather than on combinations of traits within targets: it could be that being average on a particular trait is not easy to detect but being generally average would make deviations from normality in specific traits easier to detect.

In conclusion, the present research expanded upon recent findings (Wu et al., 2016) by suggesting a similar kind of performance in people's capabilities of inferring the big-five traits, in which people tend to be imprecise in judging many targets as average but when they judge a target as being other than average, they tend to be correct. This ability is apparent in the sample from Malaysia and the sample from the UK. These results suggest that being able to detect who is unique may be especially adaptive in explaining or predicting behaviors and thus plays an important part in first 
impression formation in social life. Given the modest sample-sizes of targets in the current study, larger-scale future replications will contribute a more nuanced picture of this newly-discovered insight into person perception. 


\section{References}

Albright, L., Kenny, D. A., \& Malloy, T. E. (1988). Consensus in personality judgments at zero acquaintance. Journal of Personality and Social Psychology, 55, 387-395. doi:10.1037/0022-3514.55.3.387

Ambady, N., Bernieri, F., \& Richeson, J. (2000). Towards a histology of social behavior: Judgmental accuracy from thin slices of behavior. In Zanna, M. P. (Ed.), Advances in experimental social psychology (pp. 201-272). New York, NY: Academic Press.

Back, M. D., \& Nestler, S. Judging personality. In Hall, J. A., Schmidt Mast, M., \& West, T. V. (Eds.) (2016). The social psychology of perceiving others accurately. Cambridge University Press.

Baron-Cohen, S., \& Wheelwright, S. (2004). The empathy quotient: An investigation of adults with Asperger Syndrome or High Functioning Autism, and normal sex differences. Journal of Autism and Developmental Disorders, 34, 163-175. doi:10.1023/B:JADD.0000022607.19833.00

Biesanz, J. C., \& Human, L. J. (2010). The cost of forming more accurate impressions: Accuracy-motivated perceivers see the personality of others more distinctively but less normatively than perceivers without an explicit goal. Psychological Science, 21 (4), 589-594. doi:10.1177/0956797610364121 Borkenau, P., \& Liebler, A. (1992). Trait inferences: Sources of validity at zero acquaintance. Journal of Personality and Social Psychology, 62, 645-657. doi:10.1037/0022-3514.62.4.645 
Borkenau, P., \& Liebler, A. (1993). Convergence of stranger ratings of personality and intelligence with self-ratings, partner ratings, and measured intelligence. Journal of Personality and Social Psychology, 65, 546-553. doi:10.1037/0022-3514.65.3.546 Borkenau, P., \& Ostendorf, F. (1998). The Big Five as states: How useful is the FiveFactor Model to describe intraindividual variations over time? Journal of research in personality, 32, 202-221. doi:10.1006/jrpe.1997.2206

Borkenau, P., Mauer, N., Riemann, R., Spinath, F., \& Angleitner, A. (2004). Thin slices of behavior as cues of personality and intelligence. Journal of Personality and Social Psychology, 86, 599-614. doi:10.1037/0022-3514.86.4.599

Carney, D. R., Colvin, C. R., \& Hall, J. A. (2007). A thin slice perspective on the accuracy of first impressions. Journal of Research in Personality, 41, 1054-1072. doi:10.1016/j.jrp.2007.01.004

Clark, S. E. (2012). Costs and benefits of eyewitness identification reform: Psychological science and public policy. Perspectives on Psychological Science, 7, 238-259. doi:10.1177/1745691612439584

Cohen, J. (1988). Statistical Power Analysis for the Behavioral Sciences. New Jersey: Lawrence Erlbaum Associates.

Colvin, C. R. (1993). "Judgable" people: Personality, behavior, and competing explanations. Journal of Personality and Social Psychology, 64, 861-873. doi: $10.1037 / / 0022-3514.64 .5 .861$

Connelly, B. S., \& Ones, D. S. (2010). An other perspective on personality: Metaanalytic integration of observers' accuracy and predictive validity. Psychological 
Bulletin, 136, 1092-1122. doi:10.1037/a0021212

Connolly, J. J., Kavanagh, E. J., \& Viswesvaran, C. (2007). The convergent validity between self and observer ratings of personality: A metaanalytic review. International Journal of Selection and Assessment, 15, 110-117. doi:10.1111/j.1468-

2389.2007.00371.x

Costa, P. T., \& McCrae, R. R. (2011). NEO ${ }^{\mathrm{TM}}$ Inventories: NEO ${ }^{\mathrm{TM}}$ Personality Inventory-3 (NEO $\left.{ }^{\text {TM}}-P I-3\right)$ Manual. Psychological Assessment Resources, Inc.

Funder, D. C. (1991). Global traits: A Neo-Allportian approach to personality. Psychological Science, 2 (1), 31-39. doi:10.1111/j.1467-9280.1991.tb00093.x

Funder, D. C., Kolar, D. C., \& Blackman, M. C. (1995). Agreement among judges of personality: Interpersonal relations, similarity, and acquaintanceship. Journal of Personality and Social Psychology, 69, 656-672. doi:10.1037/0022-3514.69.4.656

Funder, D. C. (2006). Towards a resolution of the personality triad: Persons, situations, and behaviors. Journal of Research in Personality, 40, 21-34. doi:10.1016/j.jrp.2005.08.003

Funder, D. C. (2012). Accurate personality judgment. Current Directions in Psychological Science, 21, 177-182. doi:10.1177/0963721412445309

Hirschüller, S., Egloff, B., Schnukle, S. C., Nestler, S., \& Back, M. D. (2015). Accurate judgments of neuroticism at zero acquaintance: A question of relevance. Journal of Personality, 83 (2), 221-228. doi:10.1111/jopy.12097

Human, L. J., \& Biesanz, J. C. (2013). Targeting the good target: an integrative review of the characteristics and consequences of being accurately perceived. 
Personality and Social Psychology Review, 17 (3), 248-272. doi:

\section{$10.1177 / 1088868313495593$}

John, O. P., \& Robins, R. W. (1993). Determinants of interjudge agreement on personality traits: The big five domains, observability, evaluativeness, and the unique perspective of the Self. Journal of Personality, 61, 521-553. doi: 10.1111/j.14676494.1993.tb00781.x

Kang, K., Anthoney, L. \& Mitchell, P. (2017). Seven- to 11-year-olds' ability to recognize natural facial expressions of basic emotions. Perception (in press).

Kenny, D. A., Horner, C., Kashy, D. A., \& Chu, L. (1992). Consensus at zero acquaintance: Replication, behavioral cues, and stability. Journal of Personality and Social Psychology, 62, 88-97. doi:10.1037/0022-3514.62.1.88

Lynn, S. K., \& Barrett, L. F. (2014). "Utilizing” signal detection theory. Psychological Science, 25, 1669-1673. doi:10.1177/0956797614541991 Macmillan, N. A. (2002). Signal detection theory. In Pashler, H. (Ed.) Stevens' handbook of Experimental Psychology (3nd ed.). In Wixted, J. (Ed.), Vol. 4: Methodology in experimental psychology (pp. 43-90). John Wiley \& Sons, Inc., New York.

Macmillan, N. A., \& Creelman, C. D. (2005). Detection theory: A user's guide (2nd ed.). Mahwah, NJ: Lawrence Erlbaum.

McAleer, P., Todorov, A., \& Belin, P. (2014). How do you say “Hello”? Personality impressions from brief novel voices. PLoS ONE, 9, 3, e90779. doi:10.1371/journal.pone.0090779 
McCrae, R. R., \& John, O. P. (1992). An introduction to the five-factor model and its applications. Journal of Personality, 60, 175-215. doi:10.1111/j.14676494.1992.tb00970.x

McCrae, R. R., \& Costa, P. T. (2004). A contemplated revision of the NEO FiveFactor Inventory. Personality and Individual Differences, 36 (3), 587-596. doi:10.1016/S0191-8869(03)00118-1

McCrae, R. R., Terracciano, A., et al. (2005). Personality profiles of cultures: Aggregate personality traits. Journal of Personality and Social Psychology, 89(3), 407-425. doi:10.1037/0022-3514.89.3.407

McLarney-Vesotski, A. R., Bernieri, F., Rempala, D. (2006). Personality perception: A developmental study. Journal of Research in Personality, 40, 652-674. doi:10.1016/j.jrp.2005.07.001

Naumann, L. P., Vazire, S., Rentfrow, P. J., \& Gosling, S. D. (2009). Personality judgments based on physical appearance. Personality and Social Psychology Bulletin, 35, 1661-1671. doi: 10.1177/0146167209346309

Norman, W. T., \& Goldberg, L. R. (1966). Raters, ratees, and randomness in personality structure. Journal of Personality and Social Psychology, 4, 681-691. doi:10.1037/h0024002

Oltmanns, T. F., Friedman, J. N., Fiedler, E. R., \& Turkheimer, E. (2004). Perceptions of people with personality disorders based on thin slices of behavior. Journal of Research in Personality, 38, 216-229. doi:10.1016/S0092-6566(03)00066-7 Peirce, J. W. (2007). PsychoPy - Psychophysics software in Python. Journal of 
Neuroscience Methods, 162, 8-13. doi: 10.1016/j.jneumeth.2006.11.017

Pillai, D., Sheppard, E., Mitchell, P. (2012). Can people guess what happened to others from their reactions? PLoS ONE, 7(11), e49859.

doi:10.1371/journal.pone.0049859

Pillai, D., Sheppard, E., Ropar, D., Marsh, L., Pearson, A., \& Mitchell, P. (2014).

Using other minds as a window onto the world: Guessing what happened from clues in behaviour. Journal of Autism and Development Disorders, 44, 2430-2439.

doi:10.1007/s10803- 014-2106-X

Schmitt, D. P., Allik, J., McCrae, R. R., Benet-Martínez, V. (2007). The geographic distribution of Big Five personality traits: Patterns and profiles of human selfdescription across 56 nations. Journal of Cross-cultural Psychology, 38, 173- 212. doi:10.1177/0022022106297299

Stanislaw, H., \& Todorov, N. (1999). Calculation of signal detection theory measures. Behavior Research Methods, Instruments, \& Computers, 31, 137-149. doi: 10.3758/BF03207704

Swets, J. A., Dawes, R. M., \& Monahan, J. (2000). Psychological science can improve diagnostic decisions. Psychological Science in the Public Interest, 1, 1-26. doi:10.1111/1529-1006.001

Todorov, A., \& Uleman, J. S. (2002). Spontaneous trait inferences are bound to actors' faces: Evidence from a false recognition paradigm. Journal of Personality and Social Psychology, 83, 1051-1065. doi: 10.1037/0022-3514.83.5.105 
Todorov, A., \& Uleman, J. S. (2003). The efficiency of binding spontaneous trait inferences to actors' faces. Journal of Experimental Social Psychology, 39, 549-562. doi:10.1016/S0022-1031(03)00059-3

Todorov, A., \& Uleman, J. S. (2004). The person reference process in spontaneous trait inferences. Journal of Personality and Social Psychology, 87, 482-493. doi:10.1037/0022-3514.87.4.482

Todorov, A., Pakrashi, M., \& Oosterhof, N. N. (2009). Evaluating faces on trustworthiness after minimal time exposure. Social Cognition, 27, 813-833. doi:10.1521/soco.2009.27.6.813

Thoresen, J. C., Vuong, Q. C., \& Atkinson, A. P. (2012). First impressions: Gait cues drive reliable trait judgments. Cognition, 124, 261-271. doi:10.1016/j.cognition.2012.05.018

Uleman, J. S., \& Saribay, S. A. (2012). Initial impressions of others. In K. Deaux \& M. Snyder (Eds.), Oxford handbook of personality and social psychology (pp. 337366). New York: Oxford University Press.

Wall, H. J., Taylor, P. J., Dixon, J. A., Conchie, S. M., \& Ellis, D. A. (2013). Rich contexts do not always enrich the accuracy of personality judgments. Journal of Experimental Social Psychology, 49, 1190-1195. doi:10.1016/j.jesp.2013.05.010 Watson, D. (1989). Strangers' ratings of the five robust personality factors: Evidence of a surprising convergence with self-reports. Journal of Personality and Social Psychology, 52, 120-128. doi:10.1037/0022-3514.57.1.120

Willis, J., \& Todorov, A. (2006). First impressions: Making up your mind after $100 \mathrm{~ms}$ 
exposure to a face. Psychological Science, 17, 592-598. doi:10.1111/j.1467-

9280.2006.01750.x

Wood, D., Gosling, S. D., \& Potter, J. (2007). Normality evaluations and their relation to personality traits and well-being. Journal of Personality and Social Psychology, 93, 861-879. doi:10.1037/0022-3514.93.5.861

Wu, W., Sheppard, E., \& Mitchell, P. (2016). Being Sherlock Holmes: Can we sense empathy from a brief sample of behavior? British Journal of Psychology, 107 (1), 122. doi:10.1111/bjop.12157 
Table 1: Coefficients ( $\mathrm{r}$ values) of the pairwise Pearson correlations in each trait (N, E, O, A and C) among the three scenarios (Conversation, Joke, Screen Test)

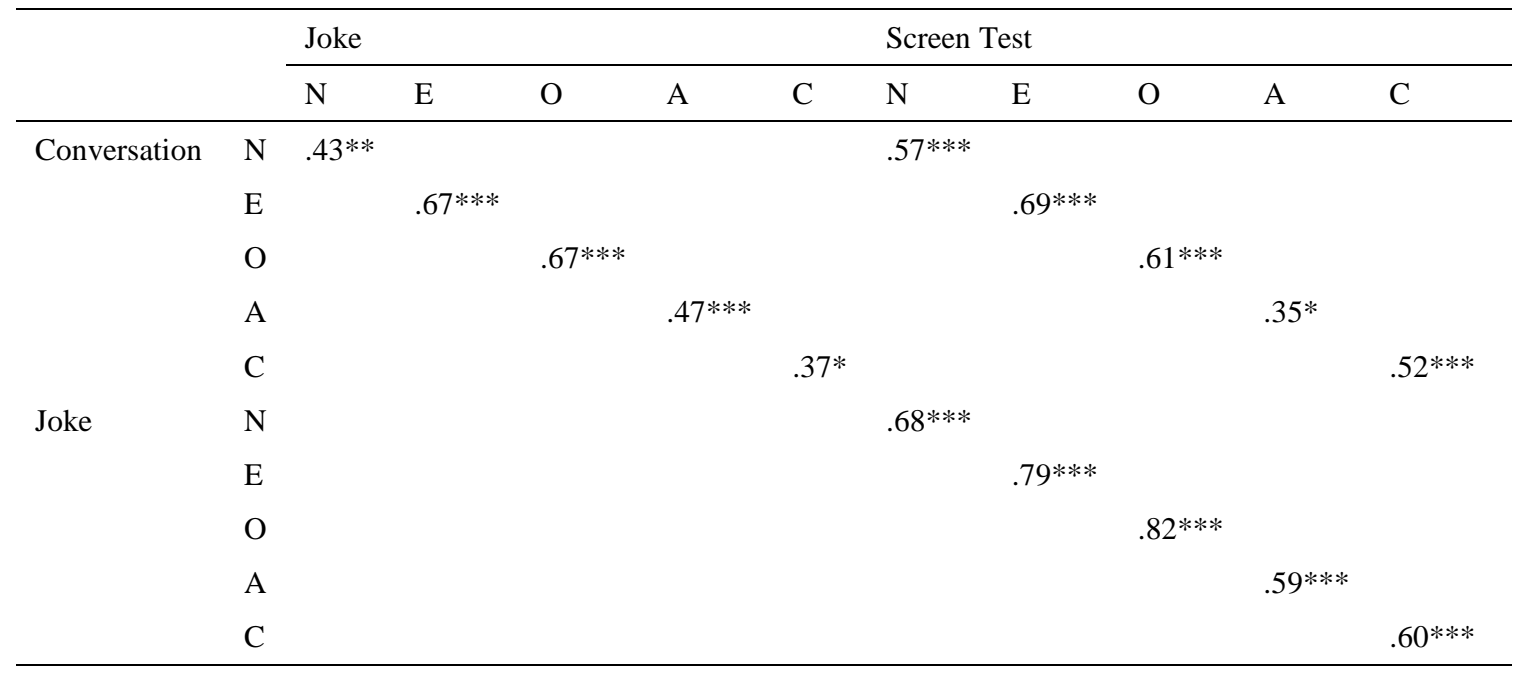

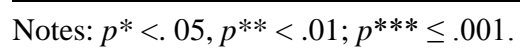


Table 2. Frequencies of perceiver judgments of target big-five traits on Levels 1-3 in Study 1

\begin{tabular}{|c|c|c|c|c|c|c|c|c|c|c|c|c|c|}
\hline \multirow{2}{*}{\multicolumn{2}{|c|}{$\begin{array}{c}\text { True Target } \\
\text { Trait }\end{array}$}} & \multicolumn{12}{|c|}{ Perceiver Response in Each Trait Level (1-3) in Each Scenario } \\
\hline & & \multicolumn{4}{|c|}{ Conversation } & \multicolumn{4}{|c|}{ Joke } & \multicolumn{4}{|c|}{ Screen Test } \\
\hline & & 1 & 2 & 3 & Total & 1 & 2 & 3 & Total & 1 & 2 & 3 & Total \\
\hline \multirow[t]{4}{*}{$\mathrm{N}$} & 1 & 120 & 96 & 24 & 240 & 89 & 106 & 45 & 240 & 108 & 100 & 32 & 240 \\
\hline & 2 & 334 & 353 & 93 & 780 & 216 & 374 & 190 & 780 & 239 & 380 & 161 & 780 \\
\hline & 3 & 171 & 166 & 53 & 390 & 102 & 174 & 114 & 390 & 145 & 183 & 62 & 390 \\
\hline & Total & 625 & 615 & 170 & & 407 & 654 & 349 & & 492 & 663 & 255 & \\
\hline \multirow[t]{4}{*}{$\mathrm{E}$} & 1 & 86 & 177 & 67 & 330 & 112 & 149 & 69 & 330 & 94 & 160 & 76 & 330 \\
\hline & 2 & 231 & 384 & 165 & 780 & 239 & 351 & 190 & 780 & 256 & 374 & 150 & 780 \\
\hline & 3 & 30 & 153 & 117 & 300 & 40 & 140 & 120 & 300 & 41 & 141 & 118 & 300 \\
\hline & Total & 347 & 714 & 349 & & 391 & 640 & 379 & & 391 & 675 & 344 & \\
\hline \multirow[t]{4}{*}{$\mathrm{O}$} & 1 & 67 & 91 & 52 & 210 & 85 & 94 & 31 & 210 & 86 & 95 & 29 & 210 \\
\hline & 2 & 215 & 418 & 177 & 810 & 278 & 379 & 153 & 810 & 243 & 409 & 158 & 810 \\
\hline & 3 & 79 & 209 & 102 & 390 & 100 & 192 & 98 & 390 & 82 & 209 & 99 & 390 \\
\hline & Total & 361 & 718 & 331 & & 463 & 665 & 282 & & 411 & 713 & 286 & \\
\hline \multirow[t]{4}{*}{ A } & 1 & 50 & 195 & 55 & 300 & 71 & 170 & 59 & 300 & 73 & 170 & 57 & 300 \\
\hline & 2 & 139 & 514 & 277 & 930 & 189 & 528 & 213 & 930 & 161 & 543 & 226 & 930 \\
\hline & 3 & 27 & 96 & 57 & 180 & 41 & 108 & 31 & 180 & 45 & 103 & 32 & 180 \\
\hline & Total & 216 & 805 & 389 & & 301 & 806 & 303 & & 279 & 816 & 315 & \\
\hline \multirow[t]{4}{*}{$\mathrm{C}$} & 1 & 92 & 218 & 110 & 420 & 83 & 229 & 108 & 420 & 67 & 213 & 140 & 420 \\
\hline & 2 & 159 & 386 & 175 & 720 & 131 & 400 & 189 & 720 & 107 & 424 & 189 & 720 \\
\hline & 3 & 27 & 154 & 89 & 270 & 46 & 150 & 74 & 270 & 32 & 147 & 91 & 270 \\
\hline & Total & 278 & 758 & 374 & & 260 & 779 & 371 & & 583 & 609 & 218 & \\
\hline
\end{tabular}

Notes: 1 = Trait Level Low, $2=$ Trait Level Average, and $3=$ Trait Level High. 
Table 3. Means (and standard deviations) of hit rate $\left(M_{H R}\right)$, false alarm rate $\left(M_{F A R}\right)$, d-prime $\left(M_{d^{\prime}}\right)$ and criterion $\mathrm{c}\left(M_{c}\right)$ in each level of each of the big-five traits across the three scenarios combined, along with the corresponding $t$ values of one-sample $t$ tests for each $M_{d}$, in Study 1

\begin{tabular}{|c|c|c|c|c|c|c|c|c|c|c|c|c|c|c|c|}
\hline \multirow[t]{2}{*}{ Traits } & \multicolumn{5}{|c|}{ Low } & \multicolumn{5}{|c|}{ Average } & \multicolumn{5}{|c|}{ High } \\
\hline & $\begin{array}{l}M_{H R} \\
(S D)\end{array}$ & $\begin{array}{c}M_{F A R} \\
(S D)\end{array}$ & $\begin{array}{c}M_{d} \\
(S D)\end{array}$ & $\begin{array}{c}M_{c} \\
(S D)\end{array}$ & $t_{d}$ & $\begin{array}{l}M_{H R} \\
(S D)\end{array}$ & $\begin{array}{r}M_{F A R} \\
(S D)\end{array}$ & $\begin{array}{c}M_{d} \\
(S D)\end{array}$ & $\begin{array}{c}M_{c} \\
(S D)\end{array}$ & $t_{d}$ & $\begin{array}{l}M_{H R} \\
(S D)\end{array}$ & $\begin{array}{c}M_{F A R} \\
(S D)\end{array}$ & $\begin{array}{c}M_{d} \\
(S D)\end{array}$ & $\begin{array}{c}M_{c} \\
(S D)\end{array}$ & $t_{d}$ \\
\hline $\mathrm{N}$ & $\begin{array}{c}.44 \\
(.23)\end{array}$ & $\begin{array}{c}.34 \\
(.20)\end{array}$ & $\begin{array}{c}.30 \\
(.47)\end{array}$ & $\begin{array}{l}.33 \\
(.63)\end{array}$ & $5.98 * *$ & $\begin{array}{c}.47 \\
(.19)\end{array}$ & $\begin{array}{c}.44 \\
(.18)\end{array}$ & $\begin{array}{c}.10 \\
(.38)\end{array}$ & $\begin{array}{c}.10 \\
(.53)\end{array}$ & $2.51 *$ & $\begin{array}{c}.20 \\
(.15)\end{array}$ & $\begin{array}{c}.14 \\
(.09)\end{array}$ & $\begin{array}{c}.23 \\
(.41)\end{array}$ & $\begin{array}{l}1.09 \\
(.52)\end{array}$ & $5.36 * *$ \\
\hline $\mathrm{E}$ & $\begin{array}{c}.30 \\
(.16)\end{array}$ & $\begin{array}{c}.26 \\
(.13)\end{array}$ & $\begin{array}{c}.12 \\
(.47)\end{array}$ & $\begin{array}{c}.67 \\
(.45)\end{array}$ & $2.40 *$ & $\begin{array}{c}.47 \\
(.16)\end{array}$ & $\begin{array}{c}.48 \\
(.15)\end{array}$ & $\begin{array}{l}-.04 \\
(.40)\end{array}$ & $\begin{array}{c}.05 \\
(.37)\end{array}$ & -.89 & $\begin{array}{c}.40 \\
(.19)\end{array}$ & $\begin{array}{c}.17 \\
(.08)\end{array}$ & $\begin{array}{c}.69 \\
(.46)\end{array}$ & $\begin{array}{c}.65 \\
(.42)\end{array}$ & $14.42 * *$ \\
\hline $\mathrm{O}$ & $\begin{array}{c}.38 \\
(.21)\end{array}$ & $\begin{array}{c}.28 \\
(.15)\end{array}$ & $\begin{array}{c}.33 \\
(.47)\end{array}$ & $\begin{array}{c}.53 \\
(.54)\end{array}$ & $6.63 * *$ & $\begin{array}{c}.50 \\
(.16)\end{array}$ & $\begin{array}{c}.49 \\
(.17)\end{array}$ & $\begin{array}{c}.01 \\
(.36)\end{array}$ & $\begin{array}{c}.01 \\
(.46)\end{array}$ & .38 & $\begin{array}{c}.26 \\
(.16)\end{array}$ & $\begin{array}{c}.16 \\
(.08)\end{array}$ & $\begin{array}{c}.35 \\
(.39)\end{array}$ & $\begin{array}{c}.91 \\
(.46)\end{array}$ & $8.52 * *$ \\
\hline A & $\begin{array}{c}.24 \\
(.18)\end{array}$ & $\begin{array}{c}.18 \\
(.13)\end{array}$ & $\begin{array}{c}.19 \\
(.56)\end{array}$ & $\begin{array}{c}.95 \\
(.51)\end{array}$ & $3.31 * *$ & $\begin{array}{c}.57 \\
(.17)\end{array}$ & $\begin{array}{c}.57 \\
(.19)\end{array}$ & $\begin{array}{l}-.04 \\
(.44)\end{array}$ & $\begin{array}{l}-.22 \\
(.48)\end{array}$ & -.79 & $\begin{array}{c}.25 \\
(.18)\end{array}$ & $\begin{array}{c}.18 \\
(.10)\end{array}$ & $\begin{array}{c}.24 \\
(.52)\end{array}$ & $\begin{array}{c}.88 \\
(.45)\end{array}$ & $4.30 * *$ \\
\hline $\mathrm{C}$ & $\begin{array}{c}.20 \\
(.16)\end{array}$ & $\begin{array}{c}.17 \\
(.13)\end{array}$ & $\begin{array}{c}.11 \\
(.50)\end{array}$ & $\begin{array}{l}1.05 \\
(.54)\end{array}$ & $2.16^{*}$ & $\begin{array}{c}.56 \\
(.17)\end{array}$ & $\begin{array}{c}.53 \\
(.17)\end{array}$ & $\begin{array}{c}.07 \\
(.38)\end{array}$ & $\begin{array}{l}-.14 \\
(.46)\end{array}$ & 1.72 & $\begin{array}{c}.32 \\
(.19)\end{array}$ & $\begin{array}{c}.20 \\
(.09)\end{array}$ & $\begin{array}{c}.36 \\
(.52)\end{array}$ & $\begin{array}{c}.72 \\
(.44)\end{array}$ & $6.63^{* *}$ \\
\hline
\end{tabular}

Note: $* p<.05, * * \mathrm{p} \leq .001, \mathrm{~N}=89$, two-tailed. Three groups of perceivers (for the Conversation and the Screen Test, $n=30$, for the Joke Scenario, $n=29$ ) viewed targets in one of three scenarios

(Conversation, Joke, Screen Test). 
Table 4. Means (and standard deviations) of hit rate $\left(M_{H R}\right)$, false alarm rate $\left(M_{F A R}\right)$, d-prime $\left(M_{d^{\prime}}\right)$ and criterion c $\left(M_{c}\right)$ in each level of each of big-five traits in each condition, along with values of onesample $t$ tests of each $M_{d}$, in Study 2

Traits Levels

Video with Audio

$M_{H R} \quad M_{F A R} \quad M_{d}, \quad M_{c} \quad t_{d}$

$(S D) \quad(S D) \quad(S D) \quad(S D)$

\section{Conditions}

Video Only

$\begin{array}{lllllllll}M_{H R} & M_{F A R} & M_{d^{\prime}} & M_{c} & t_{d}, & M_{H R} & M_{F A} & M_{d^{\prime}} & M_{c}\end{array}$

$(S D) \quad(S D) \quad(S D) \quad(S D)$
$(S D) \quad R \quad(S D) \quad(S D)$
Audio Only

$t_{d}$

$(S D)$

\begin{tabular}{|c|c|c|c|c|c|c|c|c|c|c|c|c|c|c|c|c|}
\hline \multirow[t]{5}{*}{$\mathrm{N}$} & $\mathrm{L}$ & $\begin{array}{c}.48 \\
(.26)\end{array}$ & $\begin{array}{c}.40 \\
(.22)\end{array}$ & $\begin{array}{c}.24 \\
(.46)\end{array}$ & $\begin{array}{c}.20 \\
(.69)\end{array}$ & $2.79 * *$ & $\begin{array}{c}.40 \\
(.21)\end{array}$ & $\begin{array}{c}.37 \\
(.17)\end{array}$ & $\begin{array}{c}.04 \\
(.45)\end{array}$ & $\begin{array}{c}.36 \\
(.55)\end{array}$ & .46 & $\begin{array}{c}.44 \\
(.22)\end{array}$ & $\begin{array}{c}.39 \\
(.22)\end{array}$ & $\begin{array}{c}.15 \\
(.63)\end{array}$ & $\begin{array}{c}.32 \\
(.63)\end{array}$ & 1.27 \\
\hline & A & .43 & .39 & .10 & .25 & 1.40 & .40 & .41 & -.04 & .25 & -.75 & .43 & .45 & -.08 & .12 & -1.02 \\
\hline & & $(.19)$ & $(.17)$ & $(.40)$ & (.49) & & $(.15)$ & $(.14)$ & $(.27)$ & $(.38)$ & & $(.21)$ & (.18) & $(.41)$ & (.64) & \\
\hline & $\mathrm{H}$ & .17 & .13 & .14 & 1.18 & 1.51 & .23 & .16 & .22 & .96 & $3.12 * *$ & .19 & .13 & .24 & 1.13 & $2.85^{*}$ \\
\hline & & $(.15)$ & $(.09)$ & $(.48)$ & $(.50)$ & & $(.15)$ & $(.09)$ & $(.39)$ & $(.47)$ & & (.14) & (.09) & $(.45)$ & $(.48)$ & \\
\hline \multirow[t]{6}{*}{$\mathrm{E}$} & $\mathrm{L}$ & .32 & .27 & .13 & .61 & 1.51 & .24 & .26 & -.06 & .76 & -.81 & .29 & .21 & .28 & .80 & $2.91 *$ \\
\hline & & $(.20)$ & $(.14)$ & $(.47)$ & $(.48)$ & & $(.14)$ & $(.12)$ & $(.42)$ & $(.44)$ & & $(.15)$ & $(.10)$ & $(.53)$ & $(.44)$ & \\
\hline & A & .45 & .42 & .08 & .18 & 1.01 & .46 & .51 & -.13 & .01 & -1.82 & .52 & .51 & 0 & -.12 & -.05 \\
\hline & & $(.16)$ & $(.15)$ & $(.43)$ & $(.35)$ & & $(.16)$ & $(.16)$ & $(.39)$ & $(.44)$ & & $(.17)$ & $(.15)$ & $(.41)$ & $(.55)$ & \\
\hline & $\mathrm{H}$ & .50 & .18 & .95 & .50 & $10.21 * * *$ & .35 & .19 & .46 & .68 & $5.02 * * *$ & .33 & .18 & .49 & .82 & $5.95 * *$ \\
\hline & & $(.20)$ & $(.07)$ & $(.50)$ & $(.40)$ & & $(.19)$ & $(.06)$ & $(.50)$ & $(.41)$ & & $(.17)$ & (.09) & $(.51)$ & $(.48)$ & \\
\hline \multirow[t]{6}{*}{$\mathrm{O}$} & $\mathrm{L}$ & .34 & .24 & .33 & .66 & $2.84 * *$ & .33 & .25 & .29 & .66 & $2.70 *$ & .28 & .20 & .26 & .81 & $3.18 *$ \\
\hline & & $(.22)$ & $(.15)$ & (.63) & $(.57)$ & & (.19). & $(.15)$ & $(.58)$ & $(.50)$ & & $(.16)$ & $(.10)$ & $(.44)$ & $(.45)$ & \\
\hline & A & .48 & .46 & .06 & .07 & 1.26 & .49 & .50 & -.02 & 0 & -.29 & .51 & .44 & .18 & .01 & $2.28 *$ \\
\hline & & $(.18)$ & $(.16)$ & $(.38)$ & $(.45)$ & & $(.17)$ & $(.17)$ & $(.47)$ & $(.44)$ & & $(.19)$ & $(.21)$ & $(.43)$ & $(.67)$ & \\
\hline & $\mathrm{H}$ & .34 & .21 & .38 & .67 & $4.37 * * *$ & .26 & .19 & .23 & .81 & $3.17 * *$ & .34 & .23 & .27 & .71 & $3.26^{*}$ \\
\hline & & $(.17)$ & $(.08)$ & $(.46)$ & $(.38)$ & & $(.14)$ & $(.08)$ & $(.40)$ & $(.38)$ & & $(.20)$ & $(.08)$ & $(.45)$ & $(.52)$ & \\
\hline \multirow[t]{6}{*}{ A } & $\mathrm{L}$ & .20 & .17 & .14 & 1.03 & .94 & .22 & .19 & .10 & .96 & 1.24 & .21 & .15 & .25 & 1.06 & $2.50^{*}$ \\
\hline & & $(.15)$ & $(.19)$ & $(.82)$ & $(.57)$ & & $(.17)$ & $(.11)$ & $(.46)$ & $(.49)$ & & $(.17)$ & $(.11)$ & $(.53)$ & $(.54)$ & \\
\hline & A & .53 & .56 & -.14 & -.11 & -1.18 & .51 & .53 & -.05 & -.08 & -.79 & .50 & .54 & -.10 & -.09 & -1.14 \\
\hline & & $(.17)$ & $(.16)$ & (.63) & $(.41)$ & & $(.17)$ & $(.17)$ & $(.38)$ & $(.47)$ & & $(.18)$ & (.18) & $(.47)$ & $(.56)$ & \\
\hline & $\mathrm{H}$ & .40 & .21 & .60 & .56 & $4.55^{* * *}$ & .27 & .22 & .13 & .77 & 1.63 & .39 & .22 & .54 & .62 & $5.95^{* *}$ \\
\hline & & $(.22)$ & $(.08)$ & $(.70)$ & (.43) & & $(.18)$ & $(.10)$ & $(.44)$ & $(.44)$ & & $(.24)$ & (.11) & $(.49)$ & $(.57)$ & \\
\hline \multirow[t]{6}{*}{$\mathrm{C}$} & $\mathrm{L}$ & .17 & .16 & -.02 & 1.12 & -.15 & .20 & .21 & -.04 & .96 & -.65 & .22 & .21 & .01 & .90 & .16 \\
\hline & & $(.17)$ & $(.11)$ & $(.53)$ & $(.54)$ & & $(.14)$ & $(.14)$ & $(.34)$ & $(.49)$ & & $(.16)$ & (.13) & $(.40)$ & $(.58)$ & \\
\hline & A & .55 & .59 & -.11 & -.18 & -.1 .84 & .49 & .51 & -.09 & -.03 & -1.26 & .54 & .54 & .03 & -.09 & .48 \\
\hline & & $(.17)$ & $(.19)$ & $(.33)$ & (.49) & & $(.21)$ & $(.19)$ & $(.38)$ & $(.58)$ & & $(.19)$ & (.18) & $(.39)$ & $(.50)$ & \\
\hline & $\mathrm{H}$ & .37 & .19 & .54 & .65 & $4.59 * * *$ & .30 & .22 & .21 & .70 & $2.42 *$ & .24 & .19 & .12 & .84 & 1.32 \\
\hline & & $(.23)$ & $(.08)$ & (.63) & (.48) & & $(.18)$ & $(.08)$ & $(.47)$ & $(.42)$ & & $(.18)$ & (.09) & $(.47)$ & $(.44)$ & \\
\hline
\end{tabular}

Note: Three groups ( $n=29$ in Video with Audio and in Audio Only, and $n=30$ in Video Only) of perceivers viewed or heard targets in one of the three conditions (Video with Audio, Video Only, and Audio Only);*. $p<.05, * * . p<.01 ; * * * . p<.001$, two-tailed. 
Table 5. F values of the repeated measures ANOVA in each information condition (Video with Audio, Video Only, and Audio Only) in Study 2

\begin{tabular}{cccc}
\hline ANOVA Test & Video with Audio & Video Only & Audio Only \\
\hline Main Effect of Traits & $\mathrm{F}(4,112)=2.30$ & $\mathrm{~F}(4,116)=.98$ & $\mathrm{~F}(4,126)=2.36$ \\
Main Effect of Levels & $\mathrm{F}(2,56)=65.37 * *$ & $\mathrm{~F}(2,58)=25.60 * *$ & $\mathrm{~F}(2,58)=23.34^{* *}$ \\
Interaction (Trait $\times$ Level) & $\mathrm{F}(8,224)=5.43 * *$ & $\mathrm{~F}(8,232)=5.85^{*}$ & $\mathrm{~F}(8,232)=3.04 *$ \\
\hline
\end{tabular}

Notes: $* \mathrm{p}<.01, * * \mathrm{p}<.001$ 
Table 6. Means (and standard deviations) of hit rate $\left(M_{H R}\right)$, false alarm rate $\left(M_{F A R}\right)$, d-prime $\left(M_{d^{\prime}}\right)$ and criterion c $\left(M_{c}\right)$ in each level of each of the big-five traits, along with the corresponding $t$ values of one-sample $t$ tests for each $M_{d}$, in Study 3

\begin{tabular}{|c|c|c|c|c|c|c|c|c|c|c|c|c|c|c|c|}
\hline \multirow[t]{3}{*}{ Traits } & \multicolumn{15}{|c|}{ Levels } \\
\hline & \multicolumn{5}{|c|}{ Low } & \multicolumn{5}{|c|}{ Average } & \multicolumn{5}{|c|}{ High } \\
\hline & $\begin{array}{l}M_{H R} \\
(S D)\end{array}$ & $\begin{array}{c}M_{F A R} \\
(S D)\end{array}$ & $\begin{array}{l}M_{d} \\
(S D)\end{array}$ & $M_{c}$ & $t_{d^{\prime}}$ & $\begin{array}{l}M_{H R} \\
(S D)\end{array}$ & $\begin{array}{c}M_{F A R} \\
(S D)\end{array}$ & $\begin{array}{c}M_{d} \\
(S D)\end{array}$ & $M_{c}$ & $t_{d}$ & $\begin{array}{l}M_{H R} \\
(S D)\end{array}$ & $\begin{array}{c}M_{F A R} \\
(S D)\end{array}$ & $\begin{array}{c}M_{d} \\
(S D)\end{array}$ & $M_{c}$ & $t_{d}$ \\
\hline $\mathrm{N}$ & $\begin{array}{c}.49 \\
(.23)\end{array}$ & $\begin{array}{c}.35 \\
(.17)\end{array}$ & $\begin{array}{c}.36 \\
(.63)\end{array}$ & $\begin{array}{c}.23 \\
(.50)\end{array}$ & $3.59 * *$ & $\begin{array}{c}.46 \\
(.15)\end{array}$ & $\begin{array}{c}.47 \\
(.18)\end{array}$ & $\begin{array}{l}-.02 \\
(.50)\end{array}$ & $\begin{array}{c}.09 \\
(.40)\end{array}$ & -.22 & $\begin{array}{c}.18 \\
(.13)\end{array}$ & $\begin{array}{c}.14 \\
(.09)\end{array}$ & $\begin{array}{l}.18 \\
(.58)\end{array}$ & $\begin{array}{l}1.11 \\
(.42)\end{array}$ & 1.89 \\
\hline $\mathrm{E}$ & $\begin{array}{c}.40 \\
(.23)\end{array}$ & $\begin{array}{c}.25 \\
(.12)\end{array}$ & $\begin{array}{c}.45 \\
(.62)\end{array}$ & $\begin{array}{c}.52 \\
(.45)\end{array}$ & $4.54 * *$ & $\begin{array}{c}.51 \\
(.15)\end{array}$ & $\begin{array}{c}.49 \\
(.15)\end{array}$ & $\begin{array}{c}.07 \\
(.38)\end{array}$ & $\begin{array}{c}.01 \\
(.36)\end{array}$ & 1.16 & $\begin{array}{c}.26 \\
(.12)\end{array}$ & $\begin{array}{c}.18 \\
(.05)\end{array}$ & $\begin{array}{c}.24 \\
(.39)\end{array}$ & $\begin{array}{c}.82 \\
(.26)\end{array}$ & $3.85 * *$ \\
\hline $\mathrm{O}$ & $\begin{array}{l}.50 \\
(0)\end{array}$ & $\begin{array}{c}.23 \\
(.12)\end{array}$ & $\begin{array}{c}.82 \\
(.46)\end{array}$ & $\begin{array}{c}.41 \\
(.23)\end{array}$ & $11.08^{* *}$ & $\begin{array}{c}.53 \\
(.13)\end{array}$ & $\begin{array}{c}.51 \\
(.17)\end{array}$ & $\begin{array}{c}.04 \\
(.40)\end{array}$ & $\begin{array}{l}-.07 \\
(.40)\end{array}$ & .61 & $\begin{array}{c}.28 \\
(.12)\end{array}$ & $\begin{array}{c}.18 \\
(.05)\end{array}$ & $\begin{array}{c}.31 \\
(.40)\end{array}$ & $\begin{array}{c}.78 \\
(.27)\end{array}$ & $4.90 * *$ \\
\hline A & $\begin{array}{c}.17 \\
(.14)\end{array}$ & $\begin{array}{c}.12 \\
(.09)\end{array}$ & $\begin{array}{c}.53 \\
(.13)\end{array}$ & $\begin{array}{l}1.17 \\
(.39)\end{array}$ & $2.32 *$ & $\begin{array}{c}.59 \\
(.13)\end{array}$ & $\begin{array}{c}.62 \\
(.19)\end{array}$ & $\begin{array}{l}-.11 \\
(.49)\end{array}$ & $\begin{array}{l}-.29 \\
(.41)\end{array}$ & -1.59 & $\begin{array}{c}.27 \\
(.18)\end{array}$ & $\begin{array}{c}.21 \\
(.07)\end{array}$ & $\begin{array}{l}.13 \\
(.49)\end{array}$ & $\begin{array}{c}.78 \\
(.41)\end{array}$ & 1.71 \\
\hline $\mathrm{C}$ & $\begin{array}{c}.13 \\
(.10)\end{array}$ & $\begin{array}{c}.09 \\
(.06)\end{array}$ & $\begin{array}{c}.18 \\
(.48)\end{array}$ & $\begin{array}{l}1.32 \\
(.35)\end{array}$ & $2.42^{*}$ & $\begin{array}{c}.63 \\
(.16)\end{array}$ & $\begin{array}{c}.63 \\
(.17)\end{array}$ & $\begin{array}{l}-.03 \\
(.40)\end{array}$ & $\begin{array}{l}-.37 \\
(.45)\end{array}$ & -.44 & $\begin{array}{c}.29 \\
(.19)\end{array}$ & $\begin{array}{c}.21 \\
(.08)\end{array}$ & $\begin{array}{c}.23 \\
(.56)\end{array}$ & $\begin{array}{c}.74 \\
(.37)\end{array}$ & $2.59 *$ \\
\hline
\end{tabular}

Note: $* p<.05, * * p \leqslant .001, \mathrm{~N}=39$, two-tailed. 
Figure 1.

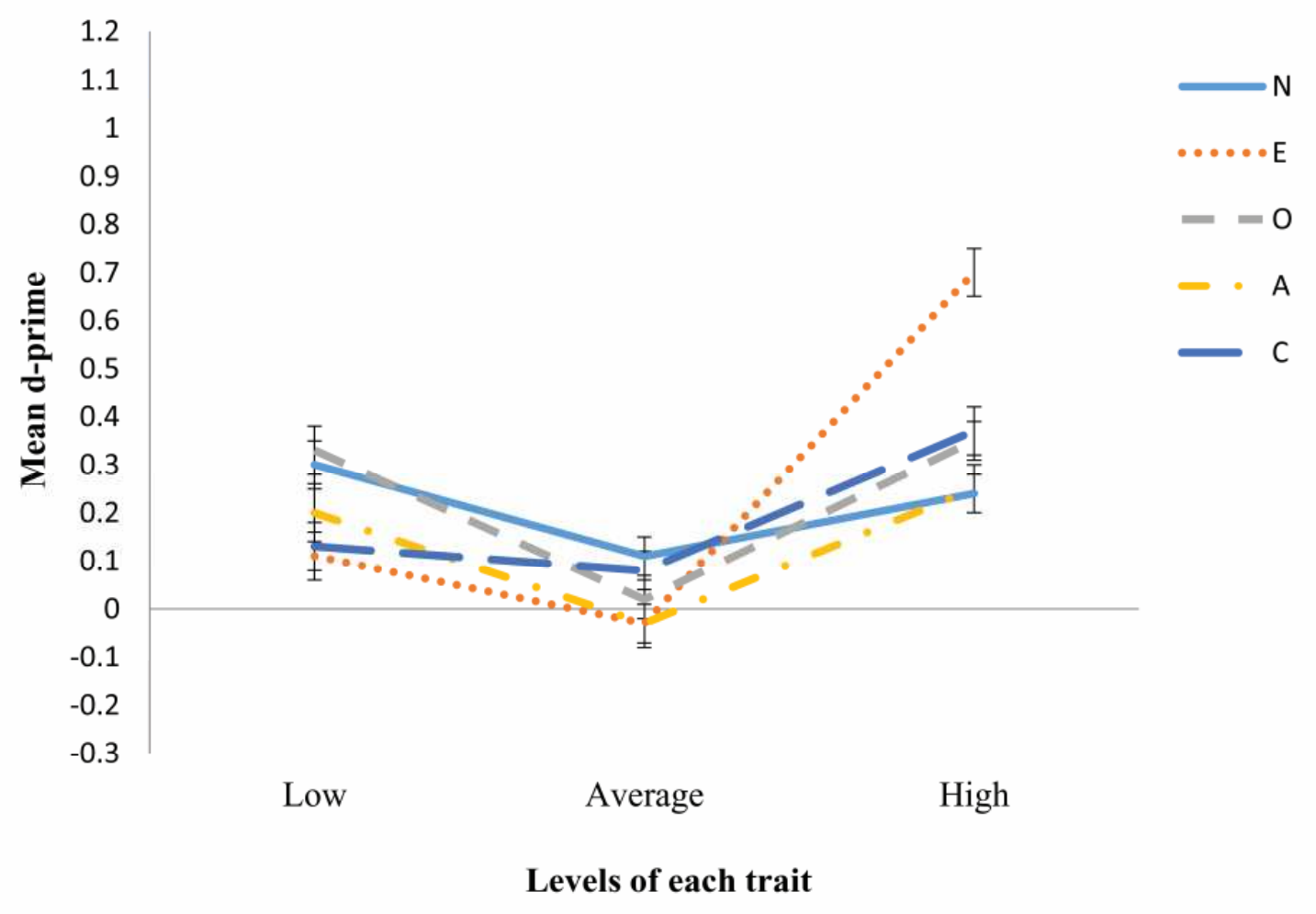




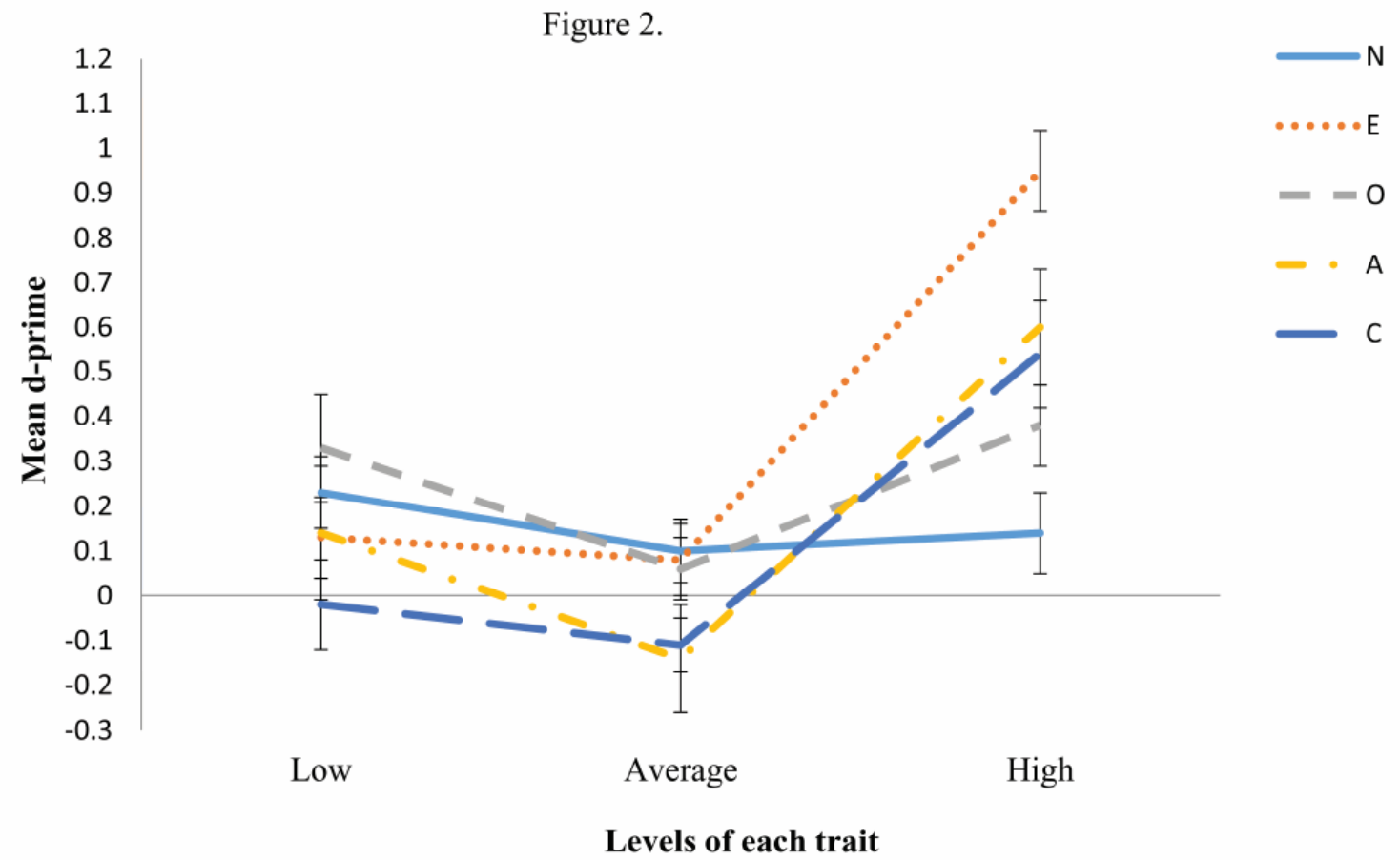


Figure 3.

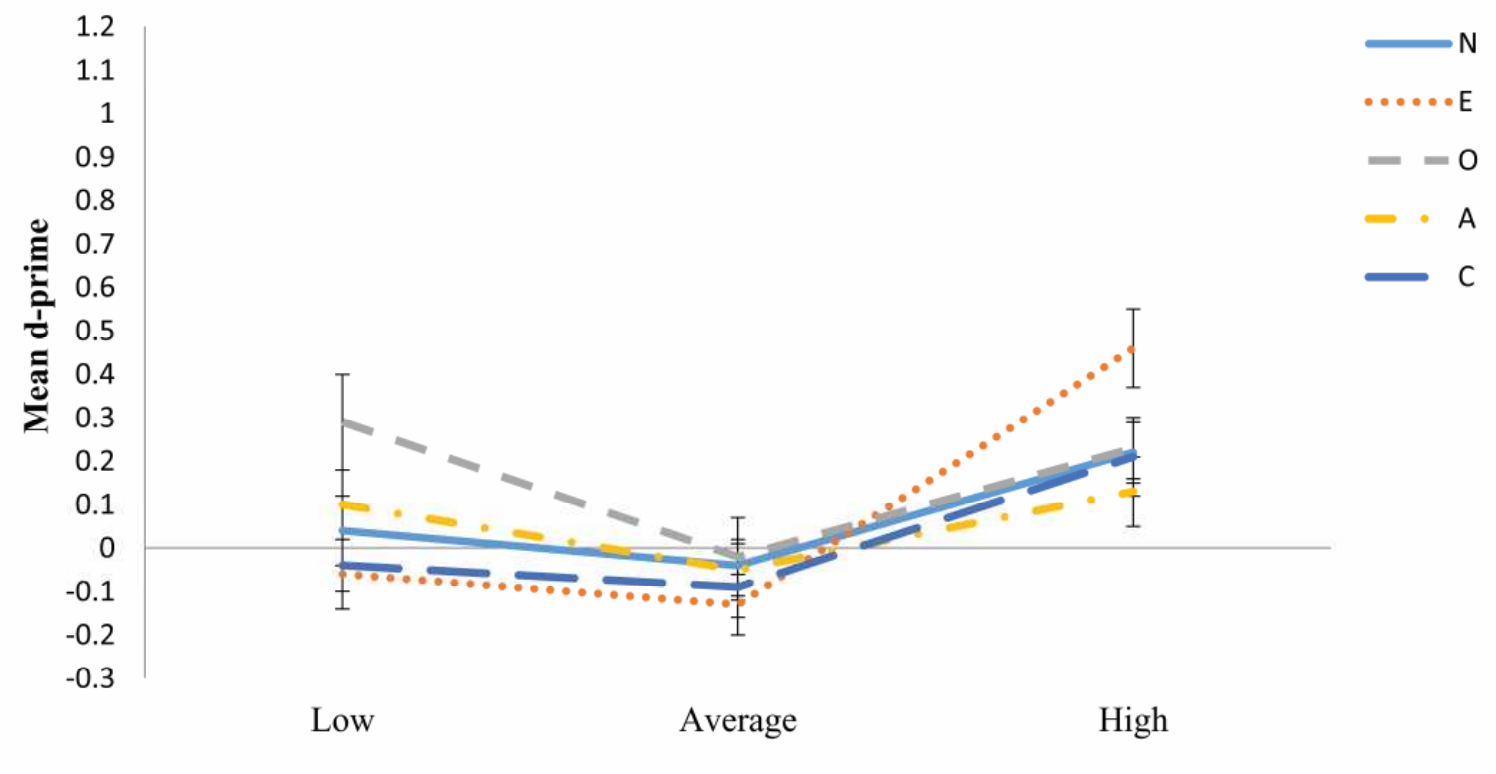

Levels of each trait 


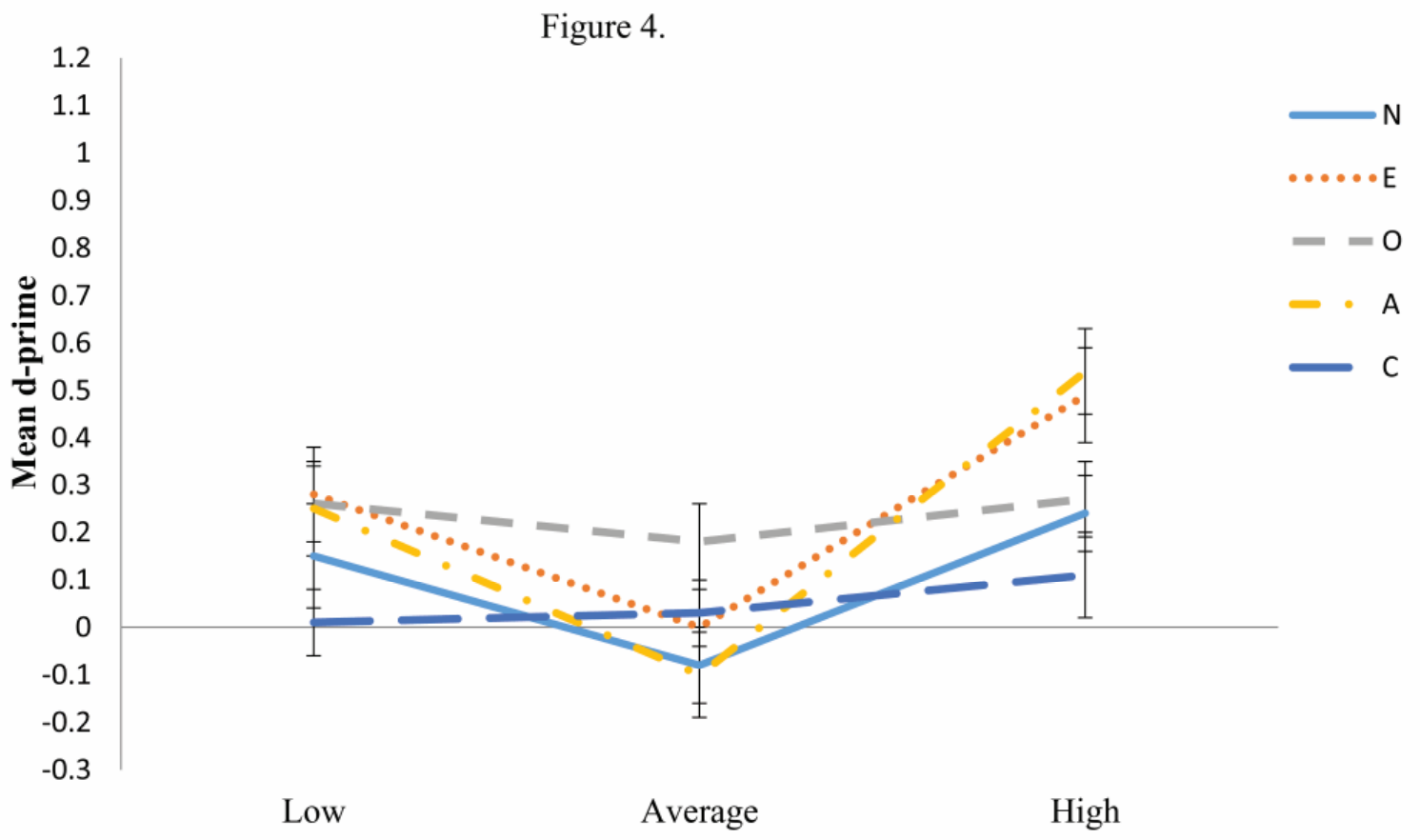

\section{Levels of each trait}




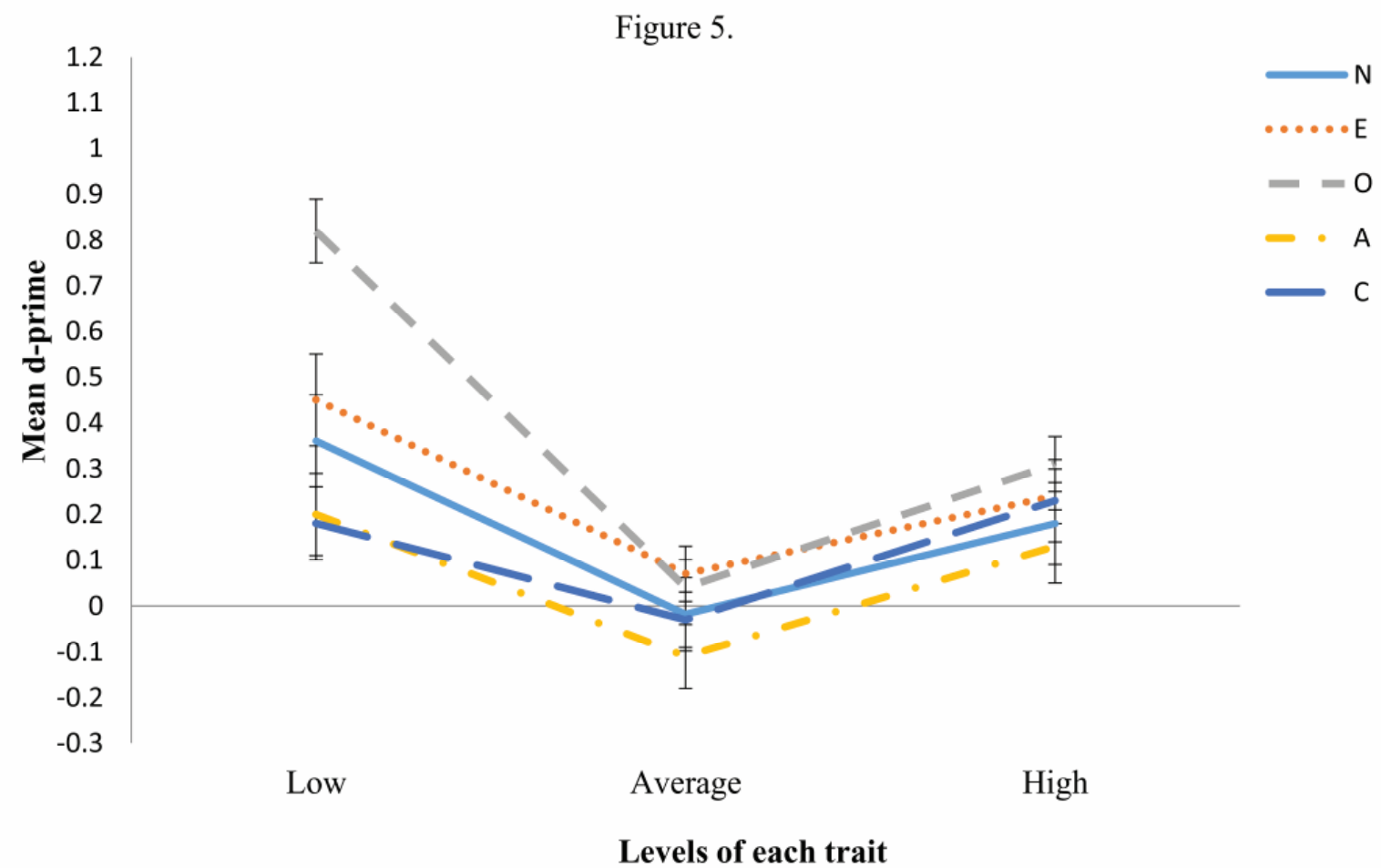

